\title{
A tutorial on laser-based lighting and visible light communications: device and technology
}

\author{
Yujian Guo (郭予健), Omar Alkhazragi (欧码), Chun Hong Kang (江隽宏), Chao Shen (沈超), \\ Yuan Mao (毛渊), Xiaobin Sun (孙晓斌), Tien Khee Ng (伍田祺) and Boon S. Ooi (黄文秀)* \\ Photonics Laboratory, King Abdullah University of Science and Technology (KAUST), Thuwal 23955-6900, Saudi Arabia \\ *Corresponding author: boon.ooi@kaust.edu.sa
}

Received October 27, 2018; accepted January 15, 2019; posted online April 8, 2019

\begin{abstract}
This tutorial focuses on devices and technologies that are part of laser-based visible light communication (VLC) systems. Laser-based VLC systems have advantages over their light-emitting-diode-based counterparts, including having high transmission speed and long transmission distance. We summarize terminologies related to laser-based solid-state lighting and VLC, and further review the advances in device design and performance. The high-speed modulation characteristics of laser diodes and superluminescent diodes, the on-chip integration of optoelectronic components in the visible color regime, such as the high-speed integrated photodetector, were introduced. The modulation technology for laser-based white light communication systems, and the challenges for future development were then discussed.
\end{abstract}

OCIS Codes: 060.2605 (free-space optical communication), 230.0230 (optical devices), 250.0250 (optoelectronics)

doi:10.3788/COL201917.040601.

\section{Introduction}

During the last decade, the demand for wireless network services has witnessed an explosive growth owing to the decrease in the cost of mobile electronic devices. The fifthgeneration (5G) wireless system requires larger bandwidth to support more users simultaneously with lower latency and higher data rates for better user experience. The wireless communication system based on conventional radio frequency $(\mathrm{RF})$ uses the frequency spectrum from 3 $\mathrm{kHz}$ to $300 \mathrm{GHz}$ and most of this range has been allocated in such a way that limits the capacity of the network. To realize an enhanced mobile broadband wireless network, light emitting diode (LED)-based visible light communication (VLC), also known as $\mathrm{Li}-\mathrm{Fi}$ [1] to combine the data transmission function with the lighting technology, has been considered a potential technology for integration into the 5G technology. This is because LEDbased VLC covers a range of $428 \mathrm{THz}(700 \mathrm{~nm})-749 \mathrm{THz}$ $(400 \mathrm{~nm})$. Further, VLC has the advantages such as high spectral efficiency, reliability, low latency, gigabit-persecond (Gbps) data rate, being robust against electromagnetic interference, and enhanced security. Therefore, VLC is a promising technology that will coexist with RF systems in future 5G technologies [2].

Table 1 [3-20] lists the selected recent progress achieved over $1 \mathrm{Gbps}$ on the VLC system in free space from 2012 to 2018. Since the early work at Keio University [21], where the team used LEDs to transmit data by visible light (1 $\mathrm{Mb} / \mathrm{s}, 1.15 \mathrm{~m}$, white LED), the work on VLC has grown gradually. In 2013, laser diodes (LDs) were proposed to replace LEDs as the transmitter in VLC links as they exhibited higher data rates and longer ranges and a 2.5 Gbps of data transmission within $1 \mathrm{~m}$ using a blue $\mathrm{LD}$ was achieved by A. E. Kelly, from the University of Glasgow [6]. More recent works on LED and LD-based VLC system were also summarized in the form of data rate versus transmission distance, as shown in Fig. 1 [20, 22-24]. The inset of Fig. 1 shows the data rate and corresponding eye diagram achieved over a 100-meter long distance using a blue $\mathrm{LD}$ demonstrated by our group [20, 22]. Depending on the application, collimated light has the advantage of longdistance transmission, while highly divergent light offers better room coverage, localization, and simultaneous lighting.

The potential applications of $\mathrm{Li}^{-} \mathrm{Fi}$ are in traffic-light-tovehicle communications, VLC in hospitals, and underwater communication. Traffic-light-to-vehicle communication is enabled by existing lighting devices that can be integrated with communication systems. With VLCbased traffic-light-to-vehicle communications, the functions of collision warnings, pre-crash sensing, turning assistance, and self-driving guidance are feasible [25]. To avoid interference with the $\mathrm{RF}$ waves of the equipment such as magnetic resonance imaging (MRI) scanners, VLC systems are likely to be implemented in the electromagnetic wave sensitive areas [26]. The utilization of VLC in underwater environments has also attracted significant attention owing to the strong absorption of $\mathrm{RF}$ waves in water and the bandwidth limitations of acoustic communication (kilohertz). Therefore, optical waves are good alternatives for underwater communication because light transmission in green and blue wavelengths has less attenuation in water than in other ranges of wavelength. Since 2015, underwater wireless optical communication (UWOC) has appeared as an emerging topic with the first Gbps data rate demonstrated in early 2008 [27]. In 2015, Hassan et al. [28] achieved a 4.8-Gbps data rate over a 5-m working distance in a UWOC system with the 16-QAMOFDM modulation scheme. Following that, in 2017, Shen et al. [29] demonstrated a 20-m UWOC link with a 1.5Gbps data rate transmission using on-off keying nonreturn-to-zero (OOK-NRZ) modulation scheme. A recent review on UWOC can be found in [23, 30]. In 2018, Li et al. [31] achieved a 5-m, 25-Gbps data rate UWOC system. Fig. 2 shows the recent research progress in UWOC [27, 28, 3140]. In contrast to LEDs, LD and superluminescent diode 
Table 1. Recent progress in VLC systems

\begin{tabular}{lccccc}
\hline \hline Year & Transmitter & Data Rate (Gbps) & Distance $(\mathrm{m})$ & Modulation & Ref. \\
\hline $\mathbf{2 0 1 2}$ & pc-LED & 1.1 & 0.23 & CAP & {$[3]$} \\
2012 & RGB-LED & 3.4 & 0.3 & OFDM (WDM) & {$[4]$} \\
2013 & RGB-LED & 3.22 & 0.25 & CAP (WDM) & {$[5]$} \\
2013 & Blue LD & 2.5 & 0.1 & OOK-NRZ & {$[6]$} \\
2014 & GaN $\mu-L E D$ & 3 & 0.05 & OFDM & {$[7]$} \\
2014 & Red LD & 12.5 & 5 & 16 -QAM-OFDM & {$[8]$} \\
2015 & Blue LD + Phosphor & 4 & 0.1 & $16-$ QAM-OFDM & {$[9]$} \\
2015 & Blue LD & 9 & 5 & $64-$ QAM-OFDM & {$[10]$} \\
2015 & Blue LD + Phosphor & 2 & 0.05 & OOK & {$[11]$} \\
2016 & Blue LD + Phosphor & 2 & 1 & OOK & {$[12]$} \\
2016 & RGB-LED & 3.375 & $<1$ & PAM-8 & {$[13]$} \\
2017 & Violet $\mu-L E D$ & 11.95 & 1 & OFDM & {$[14]$} \\
2017 & Violet LED + Phosphor & 1 & 16 & OOK & {$[15]$} \\
2017 & Blue LD & 18 & 1 & $64-$ QAM-OFDM & {$[16]$} \\
2018 & RGBYC LED & 10.72 & 0.1 & $16-$ QAM-OFDM & {$[17]$} \\
2018 & Violet LD & 3.2 & 10 & $64-$ QAM DMT & {$[18]$} \\
2018 & Violet LD & 24 & 100 & OOK-NRZ & {$[20]$} \\
2018 & Blue LD & 2.3 & & & \\
\hline \hline
\end{tabular}

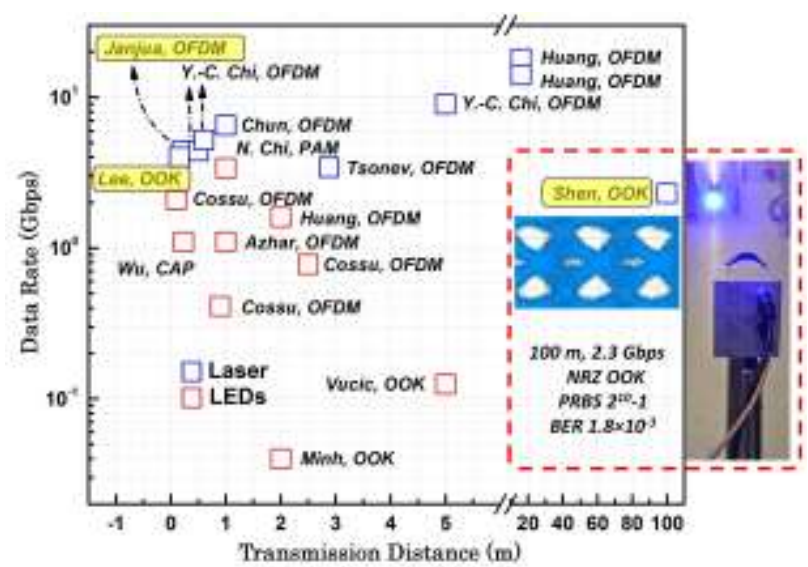

Fig. 1. Recent advances in nitride-based LED and laser-diodebased VLC [23, 24]. Modified from the work presented in Refs. $[20,22]$.

(SLD) emerge as alternative light sources for achieving high Gbps data rates owing to their short relaxation time and not being subject to problems of efficiency roll off. In 2015 , the high modulation bandwidth of $2.6 \mathrm{GHz}$ in LDs was demonstrated by Lee et al. [41], in which 4-Gbps data transmission was achieved. Taking advantage of the high modulation bandwidth in LDs compared to LEDs, the laser-based and newly emerging SLD-based VLC are considered the most competitive candidates for Gbps data rate transmission technology beyond $5 \mathrm{G}$ technologies.

In this letter, we summarize the recent progress of VLC systems in free-space environments. Section 2 explains the concepts and general terminology of VLC. Section 3 focuses on the transmitter devices in VLC. Section 4 demonstrates the modulation and equalization technology of the VLC system. In section 5, we discuss the challenges and mitigation strategies. Finally, section 6 presents the conclusions as well as the prospects of this technology.

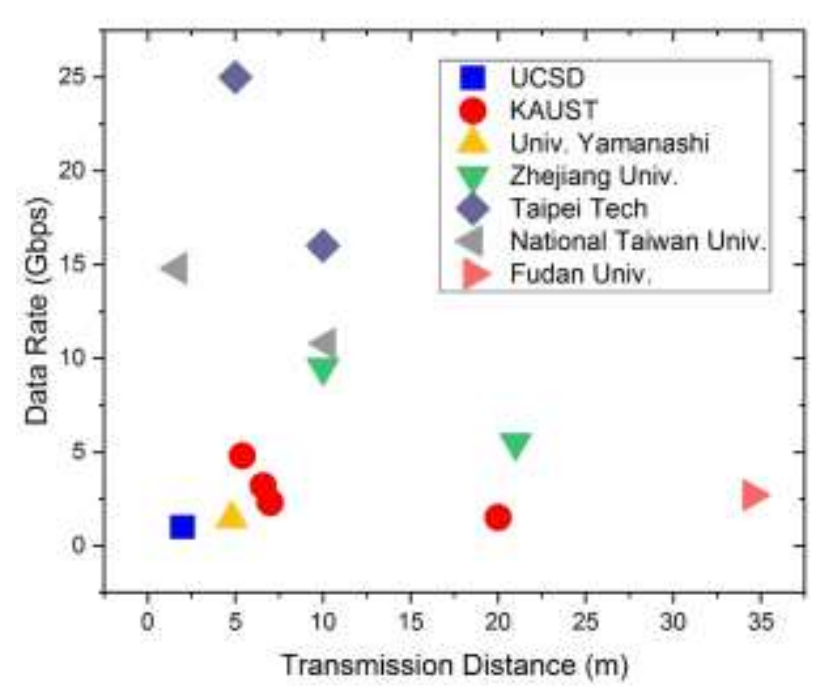

Fig. 2. Recent research progress in UWOC [27, 28, 31-40].

\section{Basic Concepts and Terminologies}

For the realization of a VLC system, the following parameters are imperative in determining the overall performance of a VLC link. In this section, we summarize some of the key terms that are closely associated with the VLC system. The terminology can be characterized into (1) white lighting characteristics, (2) performance of communication systems, and (3) photodetector characteristics.

\subsection{White lighting characteristics}

Lumen: Lumen ( $\mathrm{lm}$ ) is the international (SI) unit of luminous flux to quantify the overall light emitted by a light source. A typical 40-W incandescent light bulb usually delivers a total light output of $\sim 450 \mathrm{~lm}$, while a 9 -W LED can deliver $450 \mathrm{~lm}$.

Lux: Lux (lx) is the SI unit of illuminance, a measure of light arriving at a surface; 1 lumen per square meter equals 1 lux. The lux of LED flashlight can be up to 5,000 lux.

Candela: Candela (cd) is the SI unit of luminous intensity in a particular direction because any given light source will have different luminous intensities in different 
directions. To simplify the concept, the light from one candle can be simply compared to $1 \mathrm{~cd}$.

Beam angle: The beam angle of a lamp is the angle at which the light is emitted. It shows how the light is distributed. A beam angle of $30-40^{\circ}$ can satisfy the need of lighting from ceilings.

Correlated color temperature: The color temperature of a light source is defined as the temperature at which the color of the heated black-body radiator matches that of the light source. Correlated color temperature (CCT) is the representation of the emitted white (or nearly white) color of the light relative to the temperature of the Planckian radiator; it is measured in Kelvin (K). For a white light emitter, there are three primary types of color temperature ranges: warm white (2700 K-3000 K), cool white (3500 K$4100 \mathrm{~K})$, and daylight $(5000 \mathrm{~K}-6500 \mathrm{~K})$.

Color rendering index: Color rendering index (CRI) is a value representing color accuracy rendered under the light from a specific light source. It ranges from 0 to 100 . Taking the blackbody radiator $(\mathrm{CRI}=100)$ as a reference light source, CRI characterizes a light source's ability to reproduce the color of various objects being lit. Fluorescent light bulbs have a typical CRI of 50-70. Standard LEDs have a typical CRI of 65-85. Some high-CRI LED lamps can achieve CRIs higher than 90.

Efficacy: Efficacy $(\mathrm{lm} / \mathrm{W})$ is the efficiency of a light source to convert electric power to light. While the typical luminous efficacy of an incandescent bulb is $10-18 \mathrm{~lm} / \mathrm{W}$, the luminous efficacy of a cool-white LED is $60-92 \mathrm{~lm} / \mathrm{W}$.

Dimming range: Dimming range is the brightness range of illuminance, which reflects power and energy efficiency. However, not all lighting products are designed for dimming functions. The dimming range can be realized based on the modulation schemes or error control schemes.

Flicker range: The flicker of a light source is the fluctuation in light brightness. It can cause harmful physiological changes in people. To avoid any harmful effects, the Institute of Electrical and Electronics Engineers (IEEE) 802.15.7 standard suggests that flickering should be faster than $200 \mathrm{~Hz}$. The mitigation strategy uses run-length-limited codes.

\subsection{Performance of communication systems}

Bandwidth: Bandwidth characterizes the available signal range for our application. It can also be used to characterize the throughput of a certain system. It depends on the upper and lower frequencies in a continuous band of frequencies that can be used in the system. In VLC systems, higher unregulated bandwidths are available, and therefore, higher speeds are theoretically achievable.

Bit error rate: The bit error rate is the measurement of errors per unit time. It is measured using a pseudorandom sequence of bits, which is generated and transmitted through designed components, and then, it is received and compared with the generated sequence. It depends on factors such as bandwidth, transmitter power, path, used components, data rate, and interference (noise). Low bit error rate can be achieved by proper optimization of these factors.

Bit error ratio: The bit error ratio (BER) is a dimensionless measure of the number of bit errors divided by the total number of transferred bits during the study period. For instance, if the pattern generator sends one hundred bits to the receiver and one error is detected by the receiver, the bit error ratio would be 0.01 .

Forward error correction: Forward error correction (FEC) is a method of improving the reliability of data channels using a redundant way of encoding data streams. Hence, there is a way of error-detection and correction using the error correcting codes at the receiver end. This method is useful because it does not require a backchannel for corrupted or missing data. This technique can be simply done by an encoding and decoding piece of software, which does not require dual-way communication. In general, the FEC limit in the current technology standard is $3.8 \times 10^{-3}$. To utilize the FEC technique effectively, a VLC system with a BER lower than the permitted limit is imperative.

Signal-to-noise ratio: Signal-to-noise ratio (SNR) represents the separation between the amplitudes of signal and noise present in any analog (or digital) electronic circuitry. The main goal is to achieve a clear separation of signal and noise, determined by SNR. Different decoding equipment can handle different limits of SNR. In general, SNR can be calculated as

$$
S N R=\frac{\text { signal power }}{\text { noise power }} .
$$

Error vector magnitude: Error vector magnitude (EVM) is used to quantify the performance of digital transmitters and receivers; it is the distance between the real point and the ideal point in a power diagram. This value can be represented in decibels $(\mathrm{dB})$ or percentage.

Eye diagram: The eye diagram is an indicator of the quality of signals in a digital communication system. It can be easily captured using an oscilloscope. The shape of an eye diagram will depend upon various triggering signals, such as clock triggers, divided clock triggers, and pattern triggers. The noise, jitter on the eye, and differences in timing and amplitude from bit to bit will cause the eye opening to shrink.

Bit loading: Bit loading, or adaptive bit loading is a technique to allocate bits into subcarriers based on the current SNR. With this technique, it is possible to allocate a higher number of bits into subcarriers with higher SNR values while cutting down the number of bits in subcarriers with low SNR values for error prevention.

Power allocation: Power allocation is a method to distribute the total available power among all transmitters. This technique is commonly used in multipleinput-multiple-output (MIMO) communication. In addition, it is widely used by modern wireless fidelity (WiFi) routers (also known as beamforming) because it can boost power from the transmitter with the best SNR to the specified client while cutting the power for the clients with good SNR.

Spectrum efficiency: Spectrum efficiency represents the information rate that can be transmitted over a given bandwidth, and it is measured in bit/second $(\mathrm{s}) /$ hertz $(\mathrm{Hz})$. Further, spectrum efficiency provides information on the efficiency of a given bandwidth.

Channel estimation: Channel estimation is a technique to estimate the channel properties on a short-term basis during transmission using a pilot sequence, which is 


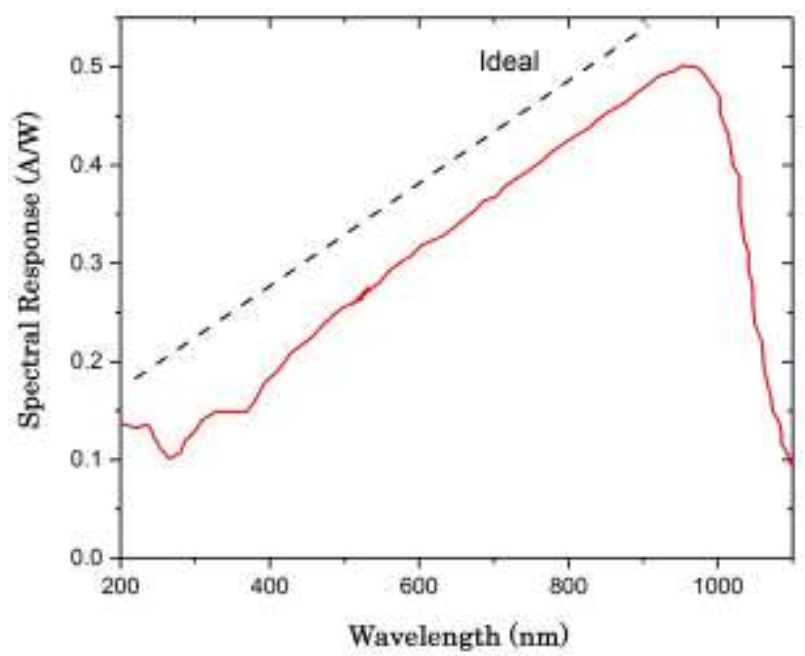

Fig. 3. Typical spectral response of Si-based photodetector

known to the transmitter and the receiver. According to the received data, channel properties can be updated.

\subsection{Photodetector characteristics}

Responsivity: Responsivity, $R$, is a measure of inputoutput gain and is measured in ampere (A)/watt (W). It represents the generated photocurrent, $I$, per value of incident optical intensity on the detector, $P_{0} . R$ depends on the wavelength and material properties of the detector and can be expressed as

$$
R=\frac{I}{P_{0}} .
$$

Quantum Efficiency: The quantum efficiency for a photodetector is defined as the number of electrons produced per incident photon. In most cases, the detector cannot convert all photons into electron-hole pairs. Quantum efficiency, $\eta$, is given by

$$
\eta=\frac{\text { number of electrons produced }}{\text { number of incident photons }}
$$

Spectral Response: The spectral response of the detector varies with the change in the wavelength of the incident radiation. Fig. 3 shows an example of the spectral response of the Si-based photodetector.

Noise Equivalent Power: Noise equivalent power is defined as the root mean square (RMS) incident power, which gives rise to a current (or voltage) whose RMS value is equal to the RMS value of the current (voltage) due to noise effects.

\section{Devices in Laser-based VLC Systems \\ 3.1. Transmitter}

As a key component of VLC, the spotlight on light emitters for enabling high data rate and modulation bandwidth is pivotal. In particular, the continuous improvement of device technology related to laser and the associated SLD is imperative. The first demonstration of the GaN-based LD grown on (0001) sapphire substrates was reported by Nakamura et al. [42]. The InGaN multiple-quantum-well (MQW)LD exhibits an emission wavelength of $417 \mathrm{~nm}$ and thus completes one of the three primary colors, i.e., red-green-blue (RGB), required for generating white-light based VLC using compact solidstate devices. In this section, we discuss the critical advances in light emitters for enabling high data rate VLC systems as illustrated in Fig. 4 [11, 12, 15, 42-51].

\subsubsection{Semipolar InGaN laser diode}

The development of GaN-based violet and blue $\mathrm{LD}$ technology in the past two decades is typically grown
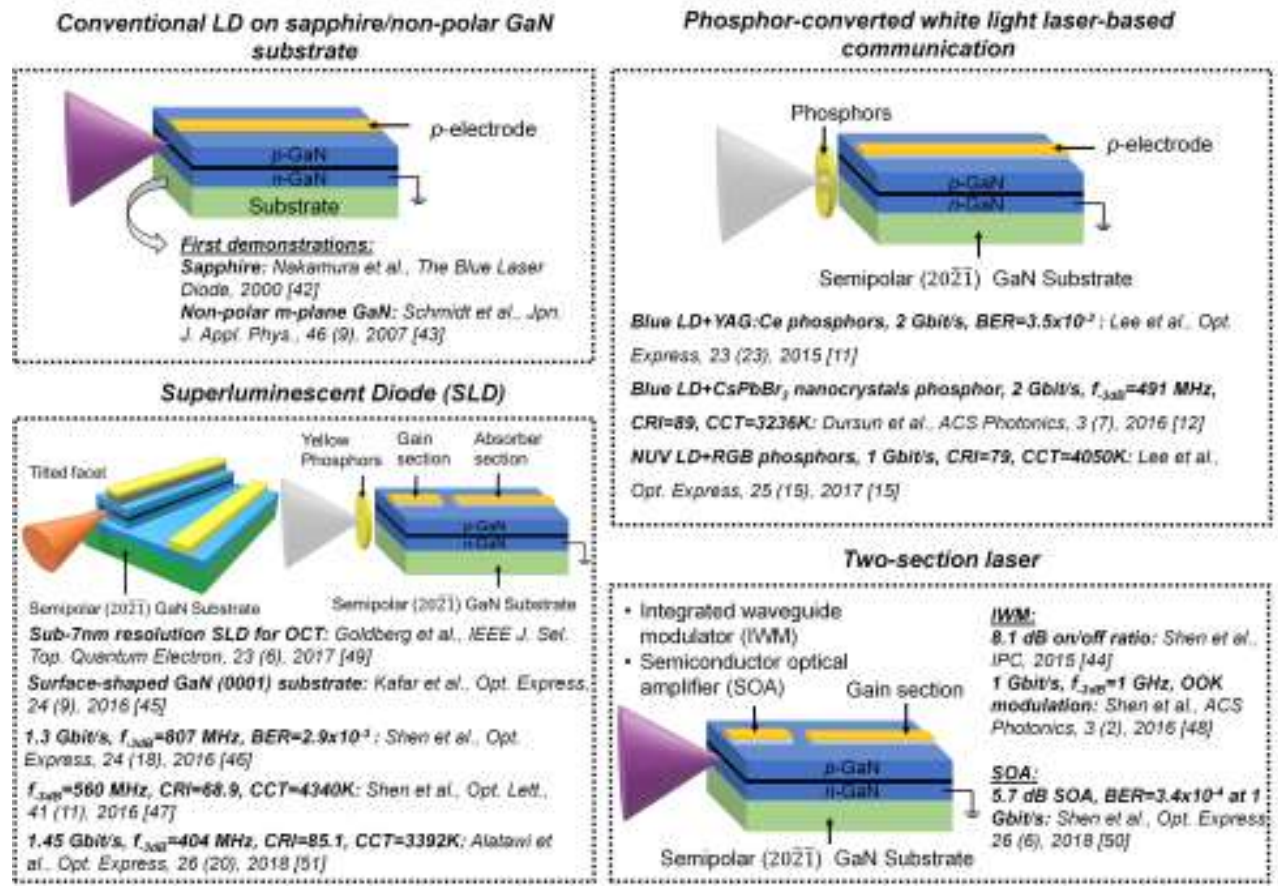

Fig. 4. Recent advances in group-III-nitride-based laser diodes and SLD for enabling high data rate VLC systems [11, 12, 15, 42-51] 
on c-plane oriented substrates, in which the polar plane suffers from strong polarization fields and reduced internal quantum efficiency [52]. Since 2007, there has been growing research interest in developing various types of InGaN LDs on non- $c$ plane GaN substrates. The LDs on an $m$-plane (a nonpolar plane) and a semipolar plane indicated their potential to outperform the devices grown on $c$ plane surfaces owing to the absence or reduction of piezo-polarization fields, respectively [43, 53]. In early 2012, Kelchner et al. reported a detailed review for the development of GaN LDs on nonpolar and semipolar planes from both material and device aspects [54]. Since then, there have been continuous efforts in improving the device performance as well as the exploration of emerging applications [55, 56]. For example, a pulsed high-power AlGaN-cladding-free blue LDs with an optical power of $2.15 \mathrm{~W}$ and external quantum efficiency (EQE) of $39 \%$ was reported [57]. The InGaN-based LD design and device performance are summarized in Table 2 [1, 58-67].

The design and fabrication of lasers should consider the active region design, optimization of the confinement factor, waveguide design, contact formation, and facet optimization. Most published works explored the utilization of asymmetric InGaN/InGaN MQW active regions [68], insertion of InGaN/GaN shallower-QW layers [69], adding a hole blocking layer prior to the first quantum barrier [70], and interface engineering [71] to reduce the threshold current density and increase the slope efficiency. Similar designs may also be implemented in fabricating semipolar InGaN-based LDs. Moreover, by incorporating transparent conducting oxide (TCO) top cladding layers into III-nitride LDs, the device performance can be improved by reducing the growth time and temperature of the p-type layers. Both indium-tin-oxide and zinc oxide ( $\mathrm{ZnO})$ have been utilized as the top cladding layer, replacing a thick $\mathrm{p}$-GaN layer to fabricate semipolar GaN LDs $[61,63,65]$. The improved thermal performance was also observed for the thin $\mathrm{p}-\mathrm{GaN} \mathrm{LDs}$ resulting in a $40 \%$ increase in peak light output power and a $32 \%$ decrease in surface temperature [61]. The waveguide design and optimization are other important design factors that have been studied [72-75]. Since the p-GaN exhibits a lower conductivity than $\mathrm{n}-\mathrm{GaN}$, there are studies to replace $\mathrm{p}^{-}$ GaN contacts with the n-GaN tunnel junction contacts for efficient hole injection [76-78]. Finally, facet formation is another critical design consideration for semipolar $\mathrm{GaN}$ LDs because of the difficulties in cleaving a semipolar GaN substrate. As alternative approaches, dry etching and polishing were proposed and demonstrated for the fabrication of semipolar LDs [64, 79, 80]. The facet etched using $\mathrm{Cl}_{2}$-based reactive ion etching (RIE) was first reported, and later, a chemically assisted $\mathrm{Ar}$ ion beam etching (CAIBE) method was demonstrated to define vertical and smooth mirror facets [80].

Here, we characterize a 410-nm emitting semipolar InGaN/GaN QW LD. Violet-emitting LDs have a similar epitaxial structure to blue-emitting $\mathrm{LDs}$ [48] except for a lower In composition in the active region, which is $\mathrm{In}_{0.1} \mathrm{Ga} 0.9 \mathrm{~N} / \mathrm{GaN} \mathrm{QWs}$. The LDs were also grown on the (2021) plane GaN substrate using

a metal-organic chemical vapor deposition (MOCVD) technique. Fig. 5(a) presents the electroluminescence

Table 2. Summary of InGaN-based laser diode design and performance

\begin{tabular}{|c|c|c|c|c|c|c|c|}
\hline Wavelength & Substrate & $\begin{array}{l}\text { Waveguide } \\
\text { design }\end{array}$ & Facet & $\begin{array}{l}\text { Optical } \\
\text { power }\end{array}$ & $\begin{array}{c}\text { Threshold } \\
\text { density }\end{array}$ & $\begin{array}{l}\text { Modulation } \\
\text { bandwidth }\end{array}$ & Ref. \\
\hline $395 \mathrm{~nm}$ & $\begin{array}{c}\text { c-plane } \\
\text { GaN }\end{array}$ & Broad area & $\begin{array}{l}\text { Cleaved, } \\
\text { uncoated }\end{array}$ & $\begin{array}{c}\text { 10-180 mW } \\
\text { (Pulse) }\end{array}$ & $\begin{array}{l}3.2-3.6 \\
\mathrm{kA} / \mathrm{cm}^{2}\end{array}$ & & [58] \\
\hline $410 \mathrm{~nm}$ & $\begin{array}{c}\text { c-plane } \\
\text { GaN }\end{array}$ & $\begin{array}{l}2-10 \mu \mathrm{m} \\
\text { ridge }\end{array}$ & $\begin{array}{c}\text { Cleaved, } \mathrm{ZrO}_{2} \\
/ \mathrm{SiO}_{2} \text { coated }\end{array}$ & $\begin{array}{c}10-75 \mathrm{~mW} \\
\quad(\mathrm{CW})\end{array}$ & - & $\begin{array}{c}2.5 \mathrm{GHz} \text { and } \\
1.38 \mathrm{GHz}\end{array}$ & [59] \\
\hline $410 \mathrm{~nm}$ & $\begin{array}{l}\text { Semipolar } \\
(20 \overline{2} \overline{1}) \text { GaN }\end{array}$ & $\begin{array}{l}2 \& 3 \mu \mathrm{m} \\
\text { ridge }\end{array}$ & RIE, uncoated & $\begin{array}{c}20-128 \mathrm{~mW} \\
\quad(\mathrm{CW})\end{array}$ & $\begin{array}{c}6.25 \\
\mathrm{kA} / \mathrm{cm}^{2}\end{array}$ & $5 \mathrm{GHz}$ & {$[1,60]$} \\
\hline $445 \mathrm{~nm}$ & $\begin{array}{l}\text { Semipolar } \\
(20 \overline{2} \overline{1}) \mathrm{GaN}\end{array}$ & $\begin{array}{l}2.5-15 \mu \mathrm{m} \\
\text { ridge }\end{array}$ & $\begin{array}{l}\text { CAIBE, } \\
\text { uncoated }\end{array}$ & $\begin{array}{l}100-1100 \\
\mathrm{~mW}(\mathrm{CW})\end{array}$ & $2.2 \mathrm{kA} / \mathrm{cm}^{2}$ & - & [61] \\
\hline $\begin{array}{c}450 \mathrm{~nm} \\
\text { (commercial) }\end{array}$ & $\begin{array}{l}\text { c-plane } \\
\text { GaN }\end{array}$ & & & $\begin{array}{l}10-70 \mathrm{~mW} \\
\quad(\mathrm{CW})\end{array}$ & - & $1.8 \mathrm{GHz}$ & {$[62]$} \\
\hline $453 \mathrm{~nm}$ & $\begin{array}{l}\text { Semipolar } \\
(20 \overline{2} 1) \mathrm{GaN}\end{array}$ & Ridge & $\begin{array}{l}\text { Polished, } \\
\text { uncoated }\end{array}$ & $\begin{array}{c}\text { 5-35 mW } \\
\text { (Pulse) }\end{array}$ & $8.6 \mathrm{kA} / \mathrm{cm}^{2}$ & - & [63] \\
\hline $457 \mathrm{~nm}$ & $\begin{array}{l}\text { Semipolar } \\
(11 \overline{2} 2) \text { GaN }\end{array}$ & $\begin{array}{c}2 \mu \mathrm{m} \text { and } 4 \\
\mu \mathrm{m} \text { ridge }\end{array}$ & $\begin{array}{l}\text { Polished, } \\
\text { uncoated }\end{array}$ & $\begin{array}{c}1-10 \mathrm{~mW} \\
\text { (Pulse) }\end{array}$ & $\begin{array}{c}13.0 \& 12.6 \\
\mathrm{kA} / \mathrm{cm}^{2}\end{array}$ & - & [64] \\
\hline $518 \mathrm{~nm}$ & $\begin{array}{l}\text { Semipolar } \\
(20 \overline{2} 1) \text { GaN }\end{array}$ & Ridge & RIE, uncoated & $\begin{array}{c}\text { 5-18 mW } \\
\text { (Pulse) }\end{array}$ & $40 \mathrm{kA} / \mathrm{cm}^{2}$ & - & [65] \\
\hline $\begin{array}{c}520 \mathrm{~nm} \\
\text { (commercial) }\end{array}$ & $\begin{array}{c}\text { c-plane } \\
\text { GaN }\end{array}$ & - & & $\begin{array}{c}10-80 \mathrm{~mW} \\
(\mathrm{CW})\end{array}$ & - & $\begin{array}{c}200-1000 \\
\mathrm{MHz}\end{array}$ & [66] \\
\hline $536.6 \mathrm{~nm}$ & $\begin{array}{l}\text { Semipolar } \\
(20 \overline{2} 1) \mathrm{GaN}\end{array}$ & $2 \mu \mathrm{m}$ ridge & $\begin{array}{c}\text { Cleaved, } \\
\text { Coated } \\
\end{array}$ & $\begin{array}{l}10-90 \mathrm{~mW} \\
(\mathrm{CW})\end{array}$ & $5.9 \mathrm{kA} / \mathrm{cm}^{2}$ & - & [67] \\
\hline
\end{tabular}



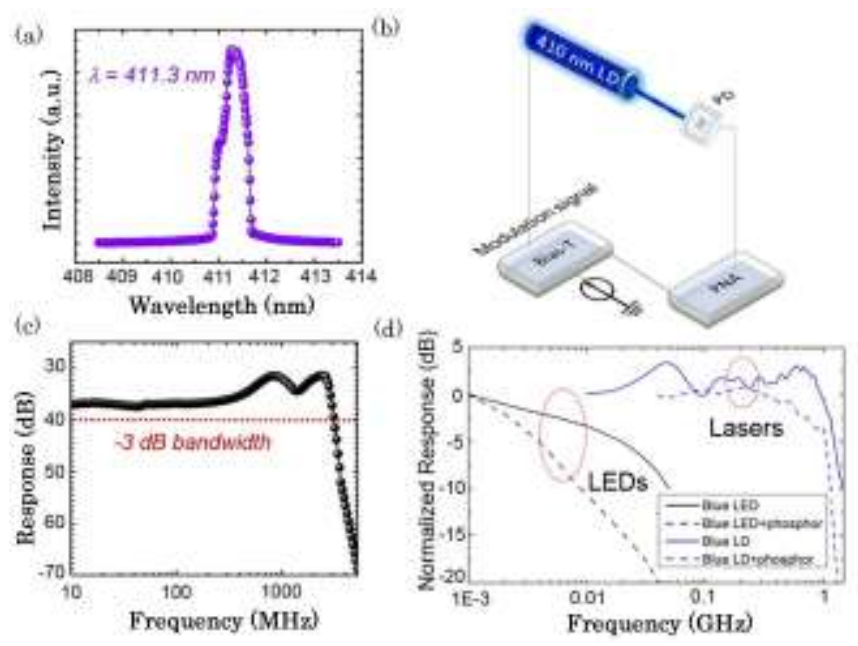

Fig. 5. (a) Electroluminescence emission spectrum of the semipolar violet-emitting laser diode at an injection current of 400 $\mathrm{mA}$. (b) Schematic of the small signal modulation response measurement setup. (c) Small signal modulation response of the violet-emitting laser diode at an injection current of $400 \mathrm{~mA}$. The laser diode shows a $-3-\mathrm{dB}$ modulation bandwidth of $\sim 3.1 \mathrm{GHz}$. (d) Comparison of modulation bandwidth in commercial LEDs and laser diodes [11].

emission spectrum of the $1500-\mu \mathrm{m}$-long violet-emitting $\mathrm{LD}$ at an injection current of $400 \mathrm{~mA}$ using an Ando AQ6315A optical spectrum analyzer. A peak emission wavelength of $411.3 \mathrm{~nm}$ was measured. The $\mathrm{LD}$ shows a single emission peak with a narrow peak full-width at half-maximum (FWHM) of $0.527 \mathrm{~nm}$. To study the high-frequency performance of the LD for VLC applications, a small signal modulation response measurement was performed using an Agilent E8361C network analyzer. Fig. 5 (b) shows the schematic of the measurement setup. The LD was probed using a custom-made prober with a high-frequency ground-signal RF probe. The setup involves a Keithley 2400 source-meter as the DC power supply, a Tektronix PSPL 5580 broadband bias-tee, and an ALPHALAS $7 \mathrm{GHz}$ UPD-50-UP high-speed $\mathrm{Si}$ photodetector (PD). A significantly large $-3 \mathrm{~dB}$ modulation bandwidth $>3 \mathrm{GHz}$ was measured from the $1500-\mu \mathrm{m}$-long violet-emitting $\mathrm{LD}$ at a driving current of $400 \mathrm{~mA}$ (Fig. 5 (c)). In typical InGaN/GaN-based quantum well LEDs, a relatively small $-3 \mathrm{~dB}$ modulation bandwidth of a few to tens of megahertz has been reported [81]. Recently, the development of microLEDs has shown improvement in extending the modulation bandwidth to hundreds of megahertz albeit at a relatively low emission power (1-2 $\mathrm{mW})$ [7, 82, 83]. However, a light source with high optical power and large modulation bandwidth, such as a $\mathrm{LD}$, is more favorable for practical VLC systems as demonstrated in Fig. 5 (d). Therefore, the GaN-LD-based platform is promising for free solid-state lighting (SSL) and VLC applications.

\subsubsection{Two-section laser and photonics integration}

$\mathrm{GaAs}^{-}$and InP-based photonics integration has been achieved in optical telecommunication wavelength regimes for many commercial applications [84]. For example, an electroabsorption modulated laser integrated with a semiconductor optical amplifier (SOA) has been developed as a compact, high-performance, and low-cost optical transmitter for access-metropolitan network convergence [85]. However, the realization of photonics integration in the visible wavelength regime remains a challenging topic. Recently, the design, fabrication, and characterization of III-nitride photonic integration, including the light emitter, waveguide modulator, amplifier, and photodetector based on multi-section devices have been reported.

In order to achieve a high-efficiency electroabsorption modulator (EAM) on a III-nitride platform and reduce the required modulation bias for low voltage operations, the waveguide modulator based on semipolar (20) $)$ QWs was demonstrated and characterized [44, 48, 86]. A comparative analysis of the photocurrent versus wavelength spectra in semipolar and polar plane InGaN/GaN quantum wells (QWs) was conducted (Fig. 6 (b)). The polar QWs exhibited a monotonic blue-shifting absorption edge with an increasing applied electric field due to the reversed quantum-confined Stark effect (QCSE) with $\mathrm{V}_{\mathrm{IM}}$ from $0 \mathrm{~V}$ to $-4 \mathrm{~V}$. In contrast, similar blue-shifting was observed when a small negative bias was applied $(0 \mathrm{~V}$ to $-1 \mathrm{~V})$ to a semipolar MQW modulator, but a red-shifting trend was observed when an increasing negative bias $(>2$ V) was applied. Such red-shifting indicates the occurrence of a QCSE-induced redshift in the absorption edge because of the applied external field on the EAM canceling the builtin polarization-induced electric fields in the active region [48]. Owing to a reduced piezoelectric field in semipolar QWs, the significant shifting of absorption edges in response to the modulation bias is effective in modulating the optical output power [48]. Our prior work investigated the first integrated electroabsorption-modulator-laser grown on semipolar (2021) GaN substrates with an on/off ratio of $8.1 \mathrm{~dB}$, demonstrating the monolithic and seamless on-chip integration of optical modulators [44].

As a building block of the high-performance transmitter in a VLC system, a dual-section LD with a semiconductor optical amplifier (SOA-LD) was demonstrated and characterized [87]. The high gain SOA-LD features the seamless integration of an SOA and an LD in the form of a $2-\mu \mathrm{m}$ ridge-waveguide fabricated on a semipolar GaN substrate (Fig. 7 (a)). The working principle of the integrated SOA is similar to that of conventional GaAsbased SOAs [88], where the waveguide mode traveling through the gain medium contributed to the optical transition of the electrically injected carriers in the conduction band. The effective gain of the dual-section SOA-LD is defined as the ratio between the optical power at the driving voltage, $V_{S O A}$, and the optical power at the transparency condition (Fig. 7 (b)). The high-gain (5.7 dB) dual-section $\mathrm{LD}$ with integrated SOA constitutes an important building block for the eventual development of large-scale III-nitride photonic integrated circuit (PIC) at the visible wavelength [50]. 
The combination of both active and passive photonic components enables the on-chip integration of optoelectronic devices with versatile functionalities [89, 90]. Benefiting from the relatively small separation between the absorption and emission peaks in semipolar InGaN/GaN quantum wells, the on-chip integration of $\mathrm{LD}$ and waveguide photodetector (WPD) has been fabricated without epitaxy regrowth in violet-blue wavelength regimes [91, 92]. Fig. 8 compares the relationship between $\mathrm{LD}$ output power and current in $\mathrm{LD}$ and the relationship between photocurrent from the WPD at zero bias and current in $\mathrm{LD}$ [91]. The WPD current is strongly correlated with the emitted optical power by the $\mathrm{LD}$, suggesting that the integrated WPD can be utilized for on-chip power monitoring. The responsivity of the InGaN-based WPD increases from $18 \mathrm{~mA} / \mathrm{W}$ to $51 \mathrm{~mA} / \mathrm{W}$ with increasing reverse bias voltage from $0 \mathrm{~V}$ to $10 \mathrm{~V}$ [91]. Since WPD and $\mathrm{LD}$ are sharing the same active layer design without the need of epitaxial regrowth, the semipolar InGaN-based WPD outperforms other QW PDs grown on polar $c$-plane substrates for simultaneous light emission and detection [93-96]. In summary, multi-section InGaN-based LDs on
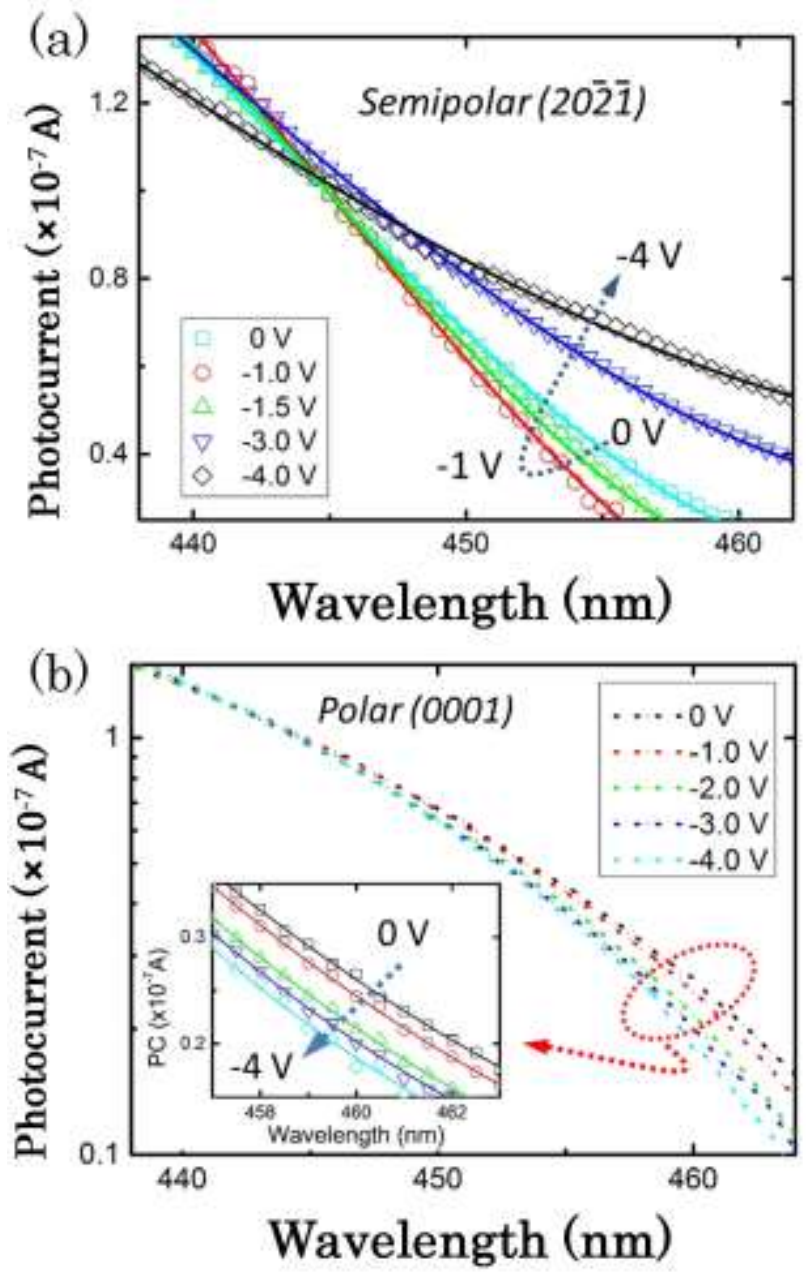

Fig. 6. Comparison of photocurrent versus wavelength spectra in: (a) semipolar (20ㄹ) and (b) c-plane (0001) InGaN/GaN QW modulators [47]. semipolar GaN substrates show promising performance for photonics integration at the visible wavelength regime.

\subsubsection{Superluminescent diode}

In recent years, nitride-based SLDs have also received significant attention owing to their optical characteristics, i.e., broadband spectrum similar to that of LEDs and high spatial coherence similar to that of LDs. Owing to its unique advantages, SLD is typically used as the source of broadband light in short-wavelength optical coherence tomography and fiber optic gyroscope systems [49]. Other examples of newly emerging applications of SLD that received increasing attention include droop-free SSL [47, 97] and VLC [46].

For nitride-based SLD, Feltin et al. [98] demonstrated for the first time the achievement of MOCVD-grown SLD emitting at $420 \mathrm{~nm}$ with peak output power of $100 \mathrm{~mW}$. Hardy et al. [99] demonstrated an m-plane blue SLD fabricated using $\mathrm{KOH}$ wet etching method. Rossetti et al.
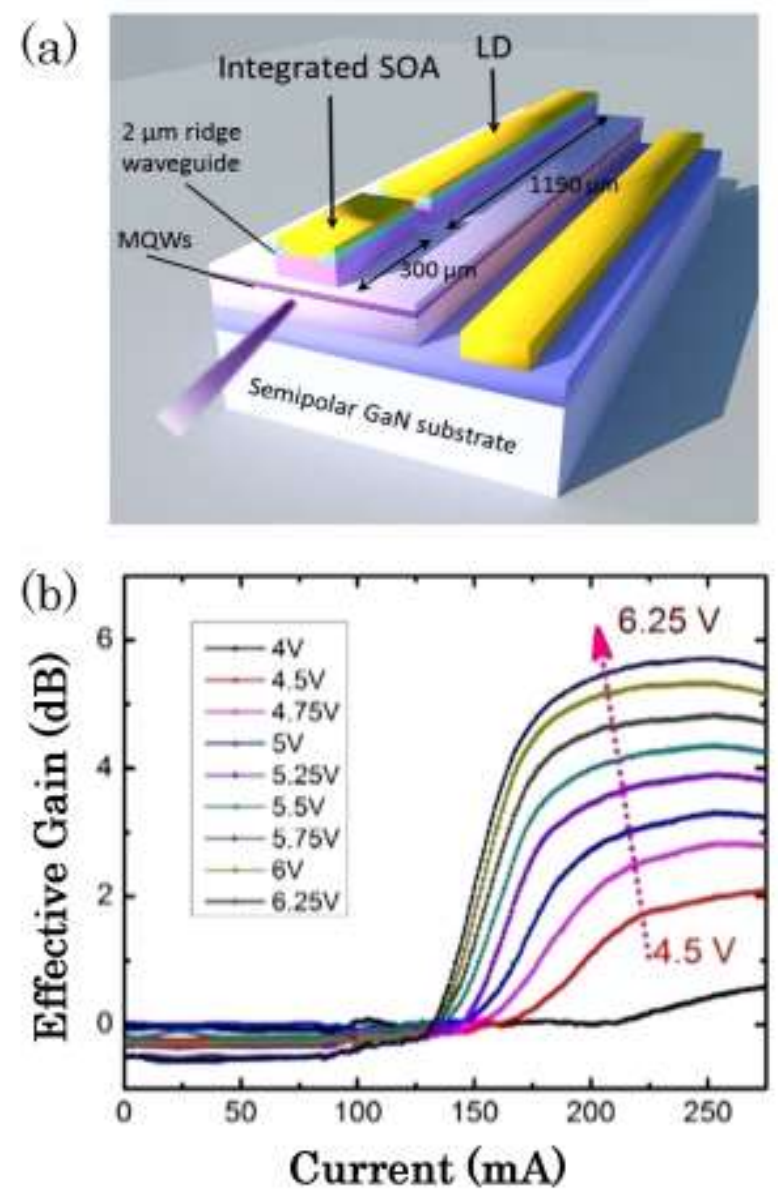

Fig. 7. (a) 3D illustration of the 405-nm emitting dual-section SOA-laser-diode on semipolar GaN substrate. The device involves four pairs of In0.1Ga0.9N/GaN MQWs as the active region and a pair of InGaN separate confinement heterostructure $(\mathrm{SCH})$ waveguide layers. The length of the SOA and laser diode is $300 \mu \mathrm{m}$ and $1190 \mu \mathrm{m}$, respectively. (b) Effective gain vs. laser current relationship of the dualsection SOA-laser-diode at different SOA bias values $\left(\mathrm{V}_{\mathrm{SOA}}\right)$ [88]. 
[100] also presented high output power and single-mode emission of blue-violet SLD using a ridge-waveguide structure and varying indium content in the active region, which could potentially lead to SLD for a number of practical applications in addition to conventional LDs and LEDs. Following these demonstrations, many studies on device optimization and system-level demonstrations have also been published. For instance, the design of waveguide structure [101, 102], SLD on semipolar/non-polar substrates [47], SLD in solid-state lighting [97], optical coherence tomography [49, 103], and optical communications [46] were demonstrated. Here, we summarize and discuss the key developments in SLD in both device- and system-level improvement, in particular, the practicality and feasibility in VLC.

The droop-free and speckle-free high optical power InGaN-based SLD for SSL was first demonstrated by Shen et al. [97] in 2016. Using the blue-emitting SLD grown on semipolar (2021) GaN substrates, the generated white light with the combination of SLD and yellow-emitting yttrium aluminum garnet (YAG: $\mathrm{Ce}^{3+}$ ) phosphor (hereafter called YAG phosphor ) demonstrated a CCT of $4340 \mathrm{~K}$ and CRI of 68.9, which are viable for indoor illumination. In the same work, the feasibility of SLD-based VLC was also demonstrated; a higher modulation bandwidth $(\sim 560$ $\mathrm{MHz})$ of SLD than that of LEDs was characterized. Later, Shen et al., presented a high modulation bandwidth SLD of up to $807 \mathrm{MHz}$ using a 405-nm InGaN-based SLD [46]. The schematic illustration of SLD with a titled facet configuration is shown in Fig. 9 (a), while the emission spectra of SLD, LDs, and LEDs are shown in Fig. 9 (b). For high-speed VLC application, by using SLD as the transmitter, data rate of $\sim 1.3 \mathrm{Gbps}$ and BER of $2.1 \times 10^{-3}$, below the FEC limit was successfully achieved with the OOK modulation scheme, thus laying a strong foundation towards SLD-based VLC applications. More recently, a high-power c-plane GaN blue (442 nm) SLD of up to 474

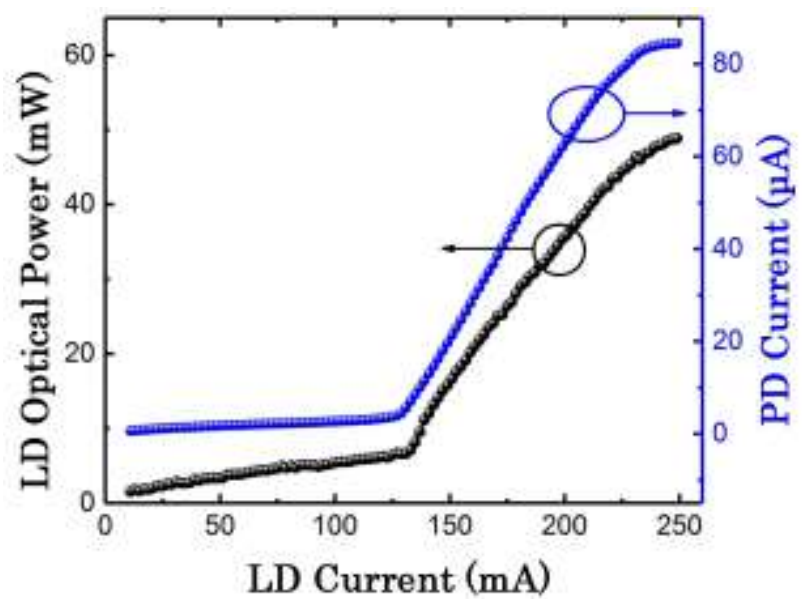

Fig. 8. Comparison of output power vs. current in laser diode, and photocurrent from the WPD at zero bias vs. current in laser diode [91].
$\mathrm{mW}$ under pulsed injection was demonstrated by Alatawi and Holguin-Lerma et al. [51] for simultaneous specklefree white lighting and wireless data communication dual functionalities. Apart from the achieved high CRI of 85.1, a record-high 1.45 Gbps communication link with BER under the FEC limit was also demonstrated, paving a way forward for speckle-free and high data rate SSL-VLC applications. Fig. 9 (c) shows the BER and data rate achieved in OOK-modulated SLD-based VLC. A detailed comparison of white light generation for dual-functionality SSL-VLC technology using conventional LEDs, laser, and proposed SLD can also be found in Shen et al. [97]. Table 3 provides a comparison and summary of the device characteristics of LEDs, LDs, and SLDs as light emitters for the SSL-VLC system.

\subsection{Phosphor for SSL-VLC}

Phosphor is a material that can release secondary optical emissions at a certain wavelength $\left(\lambda_{2}\right)$ when excited primarily by optical radiation $\left(\lambda_{1}\right)$. Phosphors can be inorganic or organic in any phase (solid, liquid, or gas). It can be categorized into down-converting phosphors, where $\lambda_{1}<\lambda_{2}$ and up-converting phosphors, where $\lambda_{1}>\lambda_{2}$. In the case of down-converting phosphors, a photon with higher energy will be converted to a photon with lower energy. However, two or more primary photons are required to emit one secondary photon for up-converting the phosphors to conserve energy. This section focuses on the downconverting phosphors.

Conventional phosphors for SSL or VLC are based on inorganic materials. They contain an inorganic host material doped with an optically active element. Garnet $\left(\mathrm{A}_{3} \mathrm{~B}_{5} \mathrm{O}_{12}\right)$ is the most commonly used host, where $\mathrm{A}$ and $\mathrm{B}$ are chemical elements and $\mathrm{O}$ is oxygen. Among the large groups of garnet, YAG is the most common material. The optical characteristics of YAG phosphors can be modified by changing the composition ratio. Fig. 10 shows the emission spectrum of Ce-doped YAG phosphors, which reveals that the increasing concentration of Ga shifts the spectrum to a shorter wavelength while the addition in $\mathrm{Gd}$ shifts the spectrum to a longer wavelength [42].

However, the long decay time for the YAG phosphor, which is on the order of microseconds, hinders the progress from being applied in the VLC system [104]. As a result, the overall bandwidth for the VLC system is limited by the phosphor within a few megahertz (3-12 MHz) [104], [105].

To overcome the bandwidth bottleneck in the YAG phosphor-based SSL-VLC system, organic materials, such as boron-dipyrromethene and poly[2,5-bis(2', 5'-bis(2'ethylhexyloxy)phenyl)-p-pheylene vinylene] (BBEHPPPV), were proposed as alternative color converters due to their visible light emission, high photoluminescence quantum yield (PLQY), direct radiation recombination, and ease of integration with nitride-based semiconductors [105-107]. The lifetime for such organic materials is shorter than YAG phosphors, which leads to a modulation bandwidth in the range of $40-200 \mathrm{MHz}$ [106]. However, a 

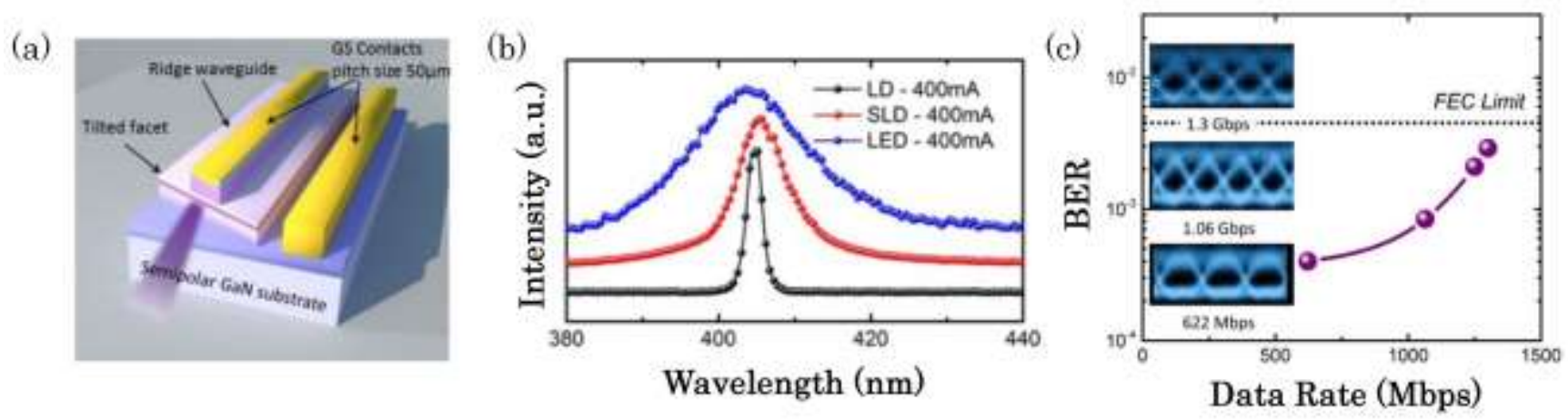

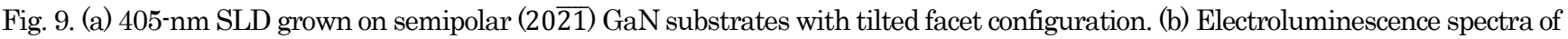
SLD in comparison with laser diode and LED at constant current injection. (c) BER versus data rate for OOK-modulated SLD-based VLC. Inset shows the corresponding eye diagrams at different data rates. [47]

Table 3. Comparison of LEDs, laser diodes, and SLDs for SSL-VLC systems

\begin{tabular}{llll}
\hline \hline Characteristics & LEDs & Laser diodes & SLDs \\
\hline Spectral width (FWHM) & 40 to $80 \mathrm{~nm}$ & 0.1 to $5 \mathrm{~nm}$ & 6 to $20 \mathrm{~nm}$ \\
\hline Modulation bandwidth & Up to tens of $\mathrm{MHz}$ & Up to few $\mathrm{GHz}$ & Up to hundreds of $\mathrm{MHz}$ \\
\hline Eye-safe level & High & Low & Moderate \\
\hline Cost & Low & High & Moderate-High \\
\hline \hline
\end{tabular}

phosphor material with a much shorter lifetime and higher efficiency is desired for high-performance SSL-VLC systems.

Recently, there has been an emerging interest in lead halide perovskites $\left(\mathrm{ABX}_{3}\right.$; where $\mathrm{A}$ is $\mathrm{G}_{3} \mathrm{NH}_{3}{ }^{+}, \mathrm{Cs}^{+}$, or $\mathrm{HC}\left(\mathrm{NH}_{2}\right)^{2+}$, $\mathrm{B}$ is $\mathrm{Pb}^{2+}$, $\mathrm{X}$ is $\mathrm{Br}$, $\mathrm{I}$, and/or $\left.\mathrm{Cl}^{-}\right)$in optoelectronic devices due to their superior performance, mobility, lifetime, and diffusion length [108]. In particular, nanocrystals $(\mathrm{NCs})$ of $\mathrm{CsPbBr}_{3}$ perovskites are attractive for white light emission [109-111] and display [112] due to their high PLQY $(\geq 70 \%)$ and short light conversion times [113]. A record perovskite-based VLC system with a modulation bandwidth of $491 \mathrm{MHz}$ was reported by Dursun et al. and is 40 times greater than that of the conventional phosphors-based VLC systems [12, 107]. In this study, $\mathrm{CsPbBr}_{3}$ perovskite was synthesized via a modified injection method [114]. With the perovskite-based VLC system, a high data rate of up to $2 \mathrm{Gbps}$ was achieved (Fig. 11 (b)). With the same perovskite material, a white- light source was strongly enhanced with a high CRI of 89 and a CCT of $3236 \mathrm{~K}$.

The laser-based SSL-VLC system requires new phosphor geometries to handle the greater light flux from the laser. Spark plasma sintering (SPS), which allows for compositional modulation and phase fraction controlling, provides the ability to create new desired phosphor geometries. Using SPS to prepare YAG phosphors combined with a chemically compatible and thermally stable oxide, $\alpha-\mathrm{Al}_{2} \mathrm{O}_{3}$, Cozzan et al. presented stable, heat-conducting phosphor composites for high-power laser lighting [115].

\section{Signal processing in VLC}

\subsection{Modulation technology}

After preprocessing, coding, and modulation, the $\mathrm{LD}$ (or LED) is driven by the original binary bit stream and electrical signals are converted into optical signals with intensity modulation. Each modulation technique has a finite number of symbols in which data can be encoded. Having more symbols allows the representation of more

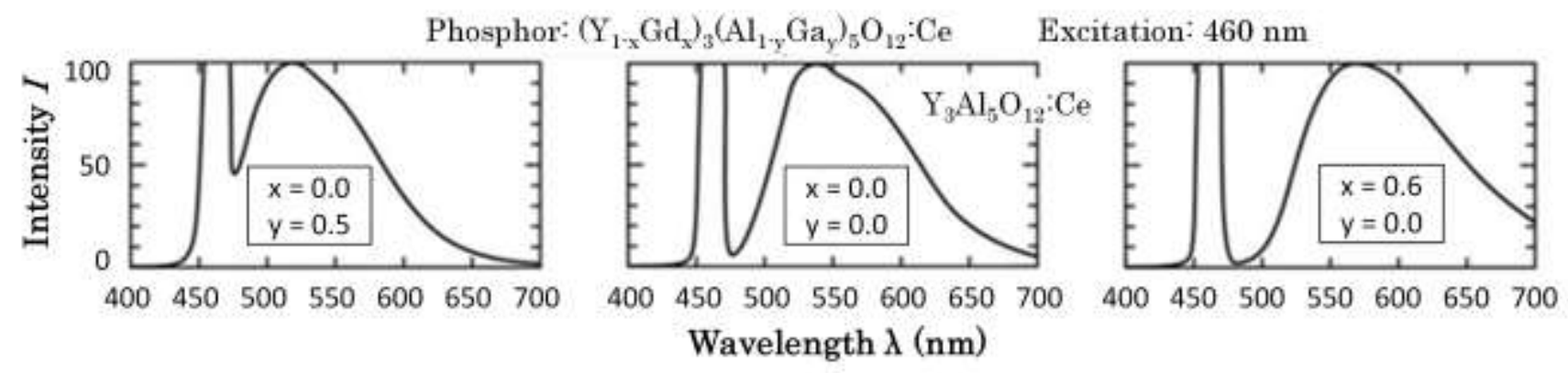

Fig. 10. Emission spectrum of Ce-doped yttrium aluminum garnet (YAG: $\mathrm{Ce}^{3+}$ ) phosphor for different chemical compositions [42] 

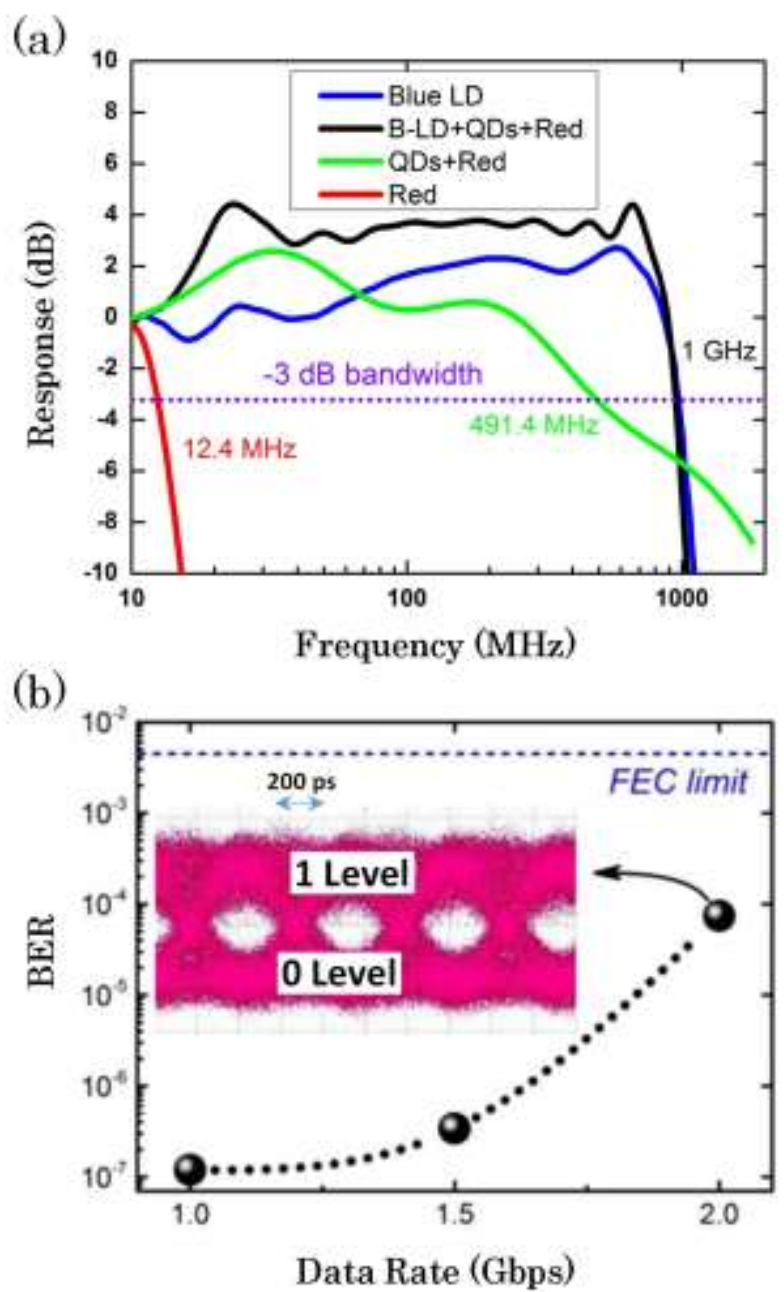

Fig. 11. (a) Measured frequency response of the perovskitebased VLC system. (b) BER of the perovskite-based VLC system at different data rate and the eye diagram of $2 \mathrm{Gbps}$ data rate showing a clear open eye [12].

bits by a single symbol. For example, if an eight-symbol modulation technique is used, each symbol can represent a set of three bits because each set can have one of eight possibilities. In general, each symbol of an $M$-symbol scheme can represent $k=\log _{2} M$ bits and these $k$ bits are mapped such that adjacent symbols differ by only one bit (Grey encoding). Therefore, the incorrect selection of adjacent symbols results in a single-bit error [116]. The use of such techniques, however, comes with an increase in the power required or a decrease in the immunity of error [117]. Some of the most commonly used modulation methods in VLC are as described in sections 4.1.1-4.1.3.

\subsubsection{On-off keying}

In on-off keying, the signal can be written as

$$
s_{\text {OoK }}(t)=A m(t) \text {, }
$$

where $m(t)$ is the signal pulse shape and $A$ has a value of one for a " 1 " bit and zero for a " 0 " bit. The waveform of this technique is shown in Fig. 12 (a). This method is called nonreturn-to-zero (NRZ), as opposed to the return-to-zero (RZ) scheme shown in Fig. 12 (b). This technique is simple and suitable for use in VLC as shown in [11, 15, 50]. The number of symbols can be increased by changing the amplitude depending on the bits to be represented by each symbol. This modulation scheme is known as pulse amplitude modulation (PAM). For example, if $A$ can take four different values, each one of them will represent two bits. Each bit can also be represented by a transition. Manchester coding, for example, uses the transition from high to low and low to high to represent " 0 " and " 1 ", respectively.

\subsubsection{Phase shift keying}

Instead of modulating the amplitude of the carrier, we can-instead modulate its phase. This method is called phase shift keying (PSK). One variation of PSK is binary PSK (BPSK), in which a "0" is represented by a phase shift of $180^{\circ}$ in the carrier and a " 1 " is represented by not changing the phase of the carrier [118]. Other PSK techniques with more symbols are also available and called $M$-ary PSK, where $M$ is the number of symbols. Increasing $M$ does not increase the required power directly, but it increases the probability of error. To double the number of symbols when $M$ is sufficiently large and to maintain the same performance, an increase of $6 \mathrm{~dB} / \mathrm{bit}$ is needed [116]. Fig. $13(\mathrm{a}, \mathrm{b})$ shows the constellation diagrams for 4PSK and 8-PSK, respectively. Grey encoding was also used to map the sets of bits to the appropriate symbols. This type of modulation was demonstrated in $[119,120]$. This scheme is possible only when orthogonal frequency division multiplexing (OFDM) is used (section 4.1.3).

\subsubsection{Quadrature amplitude modulation}

Quadrature amplitude modulation (QAM) combines both phase- and amplitude-shift keying by changing the two parameters of the carrier. For that reason, this method is also known as amplitude phase keying [117]. The number of symbols can be increased to represent more bits by a single symbol. The constellation diagrams of 4-QAM and 16-QAM are shown in Fig. 13 (c) and (d), respectively. The constellation diagrams of 4-QAM and 4-PSK are identical, but in 16-PSK, all symbols have the same amplitude, $A$, unlike 16-QAM. In [9, 121], 16-QAM was used and in [122], 64-QAM was used. The use of QAM is only possible if OFDM is applied, as will be explained in the following sub-section. However, it is possible to use carrierless amplitude and phase (CAP) modulation directly in intensity modulation. This technique uses two shaping filters that are orthogonal, one of which is for the in-phase part and the other is for the quadrature part [123].

\subsection{Multiplexing}

By using multiplexing, the data rate can be significantly increased while maintaining an acceptable error rate. There are many ways in which multiplexing can be achieved in VLC. For example, multiple wavelengths can 

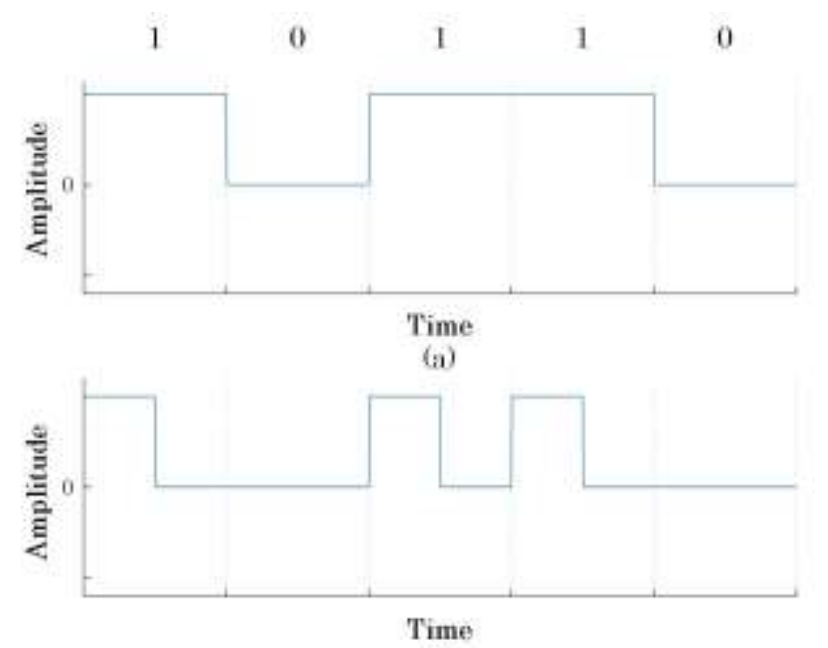

(b)

Fig. 12. Signal waveforms of different modulation techniques: (a) NRZ-OOK, and (b) RZ-OOK.

be used to transmit different data streams simultaneously. It is also possible to use different optical angular momentum modes. Spatial division multiplexing allows the use of multiple transmitters and receivers to communicate parallel data streams. One of the most commonly used multiplexing techniques is OFDM.

OFDM uses different subcarriers with orthogonal frequencies to utilize the available bandwidth efficiently. The block diagram of OFDM transmission and reception is shown in Fig. 14 [118, 124]. The serial data stream is converted to a parallel stream and then is mapped using a modulation scheme such as PSK or QAM. Hermitian symmetry is then imposed on the data stream to make sure that the output of the inverse fast Fourier transform (IFFT) in the following block is real-valued. The use of PSK or QAM is therefore possible when OFDM is employed. If the size of the IFFT is $N, N / 2$ symbols going into the IFFT will represent the data to be transmitted and the other $N / 2$ symbols will be their conjugates. This ensures that the IFFT generates only real values. Following the IFFT, the data is converted into a serial stream after a cyclic prefix is added and then the data is transmitted through the
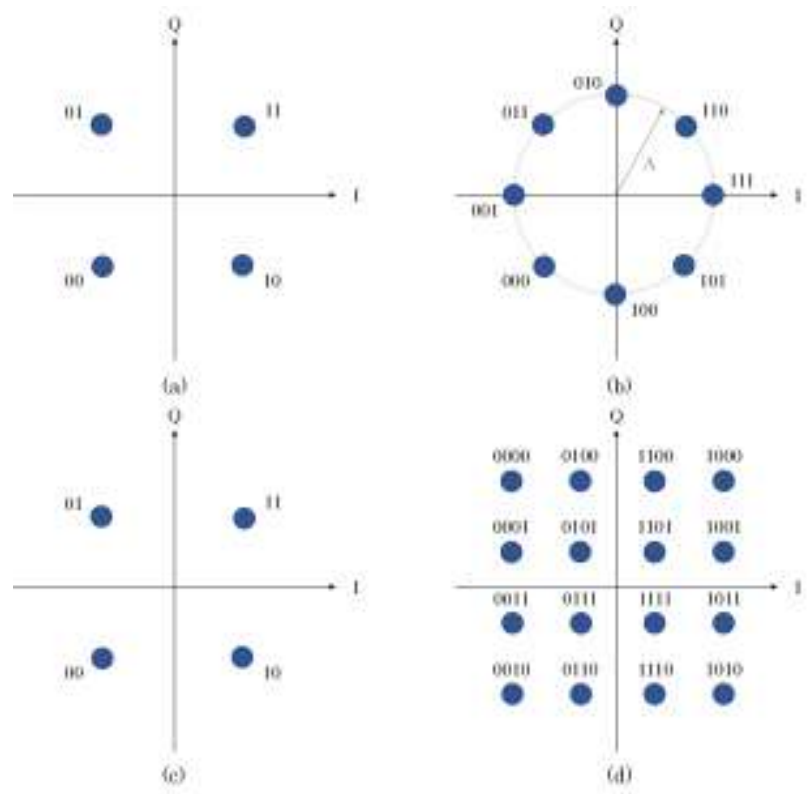

Fig. 13. Constellation diagrams of: (a) 4-PSK, (b) 8-PSK, (c) 4-QAM, and (d) 16-QAM.

channel. Since no negative values can be transmitted in optical intensity modulation, a DC bias is required.

\subsection{Equalization}

In the communication systems, the signal is often distorted when transmitted through a channel. This distortion will cause an inter-symbol interference (ISI) and contribute to the increase in the bit error rate. To improve the performance of the system, an equalizer is used to reverse the distortion.

The equalizer is also known as the equalization filter because it is a special filter that reverses the distortion by cutting down some of the unwanted components and boosting some desired components.

There are two approaches that can be used to determine the parameters of the filter: using a training sequence and blind equalization. The training requires sending a given pseudorandom binary sequence or a given code sequence and using this information to determine the distortion of the system and calculating the inverse filtering parameter

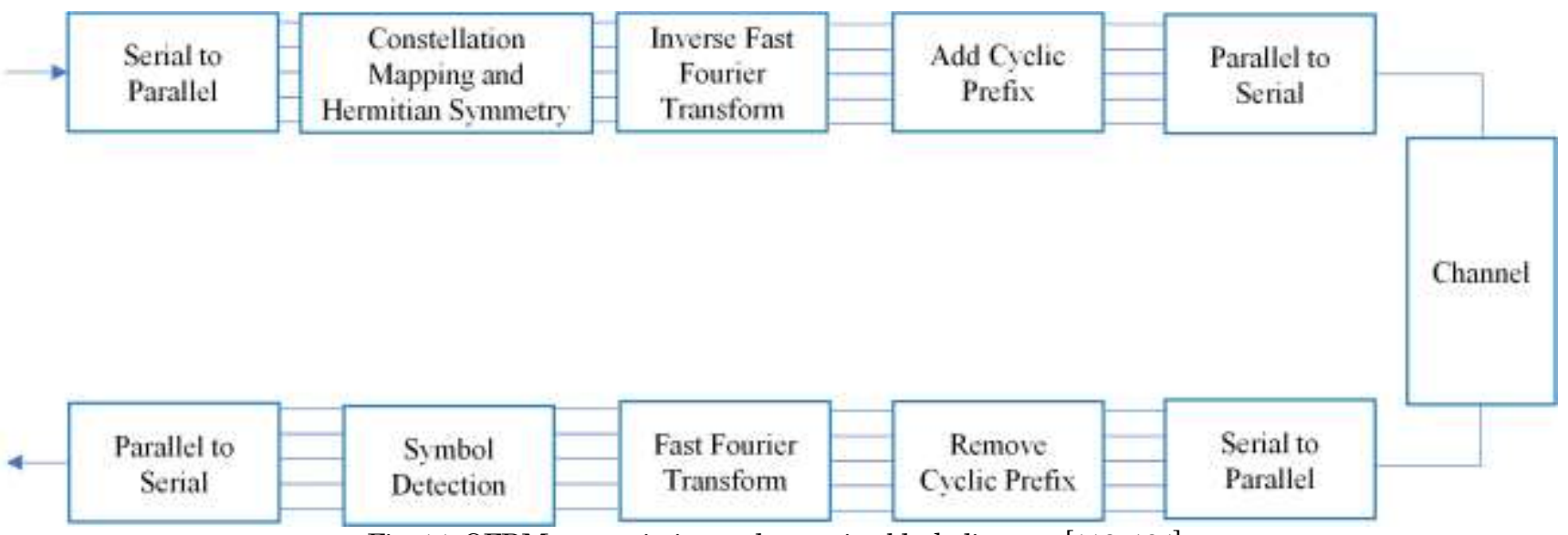

Fig. 14. OFDM transmission and reception block diagram [118, 124] 
to reverse this distortion. Blind equalization, however, requires updating the parameters until the error caused by the distortion is minimized. Therefore, it is also named adaptive filtering. The most widely used adaptive filtering methods include constant module algorithm, least mean squared equalizer, zero forcing equalization, decision feedback equalization, maximum a posteriori probability, and maximum likelihood sequence estimation.

\subsection{Optical wireless communication standards}

The IEEE standards are developed to facilitate better communication among market participants and help to accelerate the introduction of products to the market. Users of these standards should consult all applicable laws and regulations. VLC-related standards include IEEE 802.15.7, which is for short-range optical wireless communication using visible light and supports data rates up to $96 \mathrm{Mbps}$. Another standard is IEEE 802.15.13, which supports up to $10 \mathrm{Gbps}$ for wavelengths ranging from 190 $\mathrm{nm}$ to $10,000 \mathrm{~nm}$, which covers the visible light wavelength, and for a range up to $200 \mathrm{~m}$. One other standard is IEEE 802.11.bb.

\section{Challenges}

While VLC has many advantages over RF communication, it also faces unprecedented challenges that need to be mitigated. One of these challenges is commercialization, in which lighting companies and phone manufacturers have to develop their future devices to accommodate the current VLC technologies for use in future applications [125]. Another challenge is creating new VLC standards and developing the current ones by considering the latest technological evolutions in the field [126]. In addition, the performance of VLC can be degraded or distorted due to the background noise. Manchester coding mitigates this background noise [127]. Moreover, to cater for dual-functionality LD- or SLD-based SSL-VLC applications, the quality of the produced white light still needs to be improved using stable light converters that can be used for prolonged periods of time. The use of $\mathrm{LDs}$ as data transmitters also faces issues with misalignment and outages because there are many ways in which the line-ofsight link between the transmitter and the receiver might be lost or blocked. A critical concern is the hazards related to eye-safety, as long-term exposure to high-intensity light is potentially harmful to human vision and circadian rhythm [23]. In the case of using LEDs as transmitters, the limitation in allowable bandwidths would potentially limit the transmission rate in LED-based VLC systems; thus, $\mathrm{LD}$ is a more promising alternative, offering higher bandwidths and transmission rates.

\section{Conclusions}

With the increasing demand for high-speed communication and the inability of existing communication technologies to keep up with the exponentially growing demand, visible light communication, with its large unregulated bandwidth, has the potential to become the new standard for wireless communication. While it is possible to use LED-based VLC, the use of $\mathrm{LDs}$ has the additional advantage of being able to transmit data with much higher data rates. Moreover, it can also be used for dual-functionalities in VLC and SSL. This tutorial provides the reader with the necessary information about the general construction of the laserbased VLC system and methods of improving the overall system performance. After introducing the general terminology typically used in VLC systems, we described the state-of-the-art devices used as transmitters, including semipolar InGaN LDs, two-section lasers, and SLDs. Then, we discussed the use of phosphor to generate white light from lasers to cater to dual-functionality SSL-VLC systems. We also presented different modulation schemes used in VLC and the prospect of multiplexing to increase the data rate of the communication link. We also included a discussion of the use of equalization to improve the performance of a VLC system. Finally, we discussed the challenges and prospects concerning the VLC system.

Despite these challenges, the VLC technology has a great potential to be the ultimate solution to the impending crisis caused by the increasing demand for wireless communication applications that cannot be met by $\mathrm{RF}$ technology. However, there is still much work needed to overcome some of these challenges, including improving the quality of white light produced using stable light converters, misalignment between the transmitter and the receiver that can cause outages, and standardizing the technology. Based on the current trend, we anticipate exponential growth in the field of VLC and envision that the related technology can be expanded in the forthcoming years.

\section{References}

1. D. Tsonev, S. Videv, and H. Haas, "Light fidelity (Li-Fi): towards all-optical networking," in Broadband Access Communication Technologies VIII, (2014), p. 900702.

2. S. Wu, H. Wang, and C.-H. Youn, "Visible light communications for $5 \mathrm{G}$ wireless networking systems: from fixed to mobile communications," IEEE Netw. 28, 41 (2014).

3. F. Wu, C. Lin, C. Wei, C. Chen, H. Huang, and C. Ho, "1.1$\mathrm{Gb} / \mathrm{s}$ White-LED-Based Visible Light Communication Employing Carrier-Less Amplitude and Phase Modulation," IEEE Photon. Technol. Lett. 24, 1730 (2012).

4. G. Cossu, A. M. Khalid, P. Choudhury, R. Corsini, and E. Ciaramella, "3.4 Gbit/s visible optical wireless transmission based on RGB LED," Opt. Express 20, B501 (2012).

5. F.-M. Wu, C.-T. Lin, C.-C. Wei, C.-W. Chen, Z.-Y. Chen, and K. Huang, "3.22-Gb/s WDM Visible Light Communication of a Single RGB LED Employing CarrierLess Amplitude and Phase Modulation," in Optical Fiber Communication Conference/National Fiber Optic Engineers Conference 2013, OSA Technical Digest (online) (2013), p. 4.

6. S. Watson, M. Tan, S. P. Najda, P. Perlin, M. Leszczynski, G. Targowski, S. Grzanka, and A. Kelly, "Visible light 
communications using a directly modulated $422 \mathrm{~nm} \mathrm{GaN}$ laser diode," Opt. Lett. 38, 3792 (2013).

7. D. Tsonev, H. Chun, S. Rajbhandari, J. J. D. McKendry, S. Videv, E. Gu, M. Haji, S. Watson, A. E. Kelly, G. Faulkner, M. D. Dawson, H. Haas, and D. O. Brien, "A 3-Gb/s Single-LED OFDM-Based Wireless VLC Link Using a Gallium Nitride uLED," IEEE Photon. Technol. Lett. 26, 637 (2014).

8. C. Chang, C. Li, H. Lu, C. Lin, J. Chen, Z. Wan, and C. Cheng, "A 100-Gb/s Multiple-Input Multiple-Output Visible Laser Light Communication System," J. Light. Technol. 32, 4723 (2014).

9. J. R. D. Retamal, H. M. Oubei, B. Janjua, Y.-C. Chi, H.-Y. Wang, C.-T. Tsai, T. K. Ng, D.-H. Hsieh, H.-C. Kuo, M.S. Alouini, J.-H. He, G.-R. Lin, and B. S. Ooi, "4-Gbit/s visible light communication link based on 16-QAM OFDM transmission over remote phosphor-film converted white light by using blue laser diode," Opt. Express 23, 33656 (2015).

10. Y. C. Chi, D. H. Hsieh, C. T. Tsai, H. Y. Chen, H. C. Kuo, and G. R. Lin, "450-nm GaN laser diode enables highspeed visible light communication with 9-Gbps QAMOFDM," Opt. Express 23, 13051 (2015).

11. C. Lee, C. Shen, H. M. Oubei, M. Cantore, B. Janjua, T. K. Ng, R. M. Farrell, M. M. El-Desouki, J. S. Speck, S. Nakamura, B. S. Ooi, and S. P. DenBaars, "2 Gbit/s data transmission from an unfiltered laser-based phosphorconverted white lighting communication system," Opt. Express 23, 29779 (2015).

12. I. Dursun, C. Shen, M. R. Parida, J. Pan, S. P. Sarmah, D. Priante, N. Alyami, J. Liu, M. I. Saidaminov, M. S. Alias, A. L. Abdelhady, T. K. Ng, O. F. Mohammed, B. S. Ooi, and O. M. Bakr, "Perovskite Nanocrystals as a Color Converter for Visible Light Communication," ACS Photonics 3, 1150 (2016).

13. N. Chi, M. Zhang, Y. Zhou, and J. Zhao, "3.375-Gb/s RGBLED based WDM visible light communication system employing PAM-8 modulation with phase shifted Manchester coding," Opt. Express 24, 21663 (2016).

14. M. S. Islim, R. X. Ferreira, X. He, E. Xie, S. Videv, S. Viola, S. Watson, N. Bamiedakis, R. V. Penty, I. H. White, A. E. Kelly, E. Gu, H. Haas, and M. D. Dawson, "Towards $10 \mathrm{~Gb} / \mathrm{s}$ orthogonal frequency division multiplexing-based visible light communication using a $\mathrm{GaN}$ violet microLED," Photonics Res. 5(2017).

15. C. Lee, C. Shen, C. Cozzan, R. M. Farrell, J. S. Speck, S. Nakamura, B. S. Ooi, and S. P. DenBaars, "Gigabit-persecond white light-based visible light communication using near-ultraviolet laser diode and red-, green-, and blueemitting phosphors," Opt. Express 25, 17480 (2017).

16. Y.-F. Huang, Y.-C. Chi, H.-Y. Kao, C.-T. Tsai, H.-Y. Wang, H.-C. Kuo, S. Nakamura, D.-W. Huang, and G.-R. Lin, "Blue Laser Diode Based Free-space Optical Data Transmission elevated to 18 Gbps over 16 m," Sci. Rep. 7, 10478 (2017).

17. X. Zhu, F. Wang, M. Shi, N. Chi, J. Liu, and F. Jiang, "10.72Gb/s Visible Light Communication System Based On Single Packaged RGBYC LED Utilizing QAM-DMT Modulation With Hardware Pre-Equalization," in Optical Fiber Communication Conference, OSA Technical Digest (online) (2018), p. 3.

18. K.-T. Ho, R. Chen, G. Liu, C. Shen, J. Holguin-Lerma, A. A. Al-Saggaf, T. K. Ng, M.-S. Alouini, J.-H. He, and B. S. Ooi, "3.2 Gigabit-per-second Visible Light
Communication Link with InGaN/GaN MQW Microphotodetector," Opt. Express 26, 3037 (2018).

19. W.-C. Wang, H.-Y. Wang, and G.-R. Lin, "Ultrahigh-speed violet laser diode based free-space optical communication beyond 25 Gbit/s," Sci. Rep. 8, 13142 (2018).

20. B. S. Ooi, "Visible Light Communication," in Pacific Rim Conference on Lasers and Electro-Optics (CLEO-PR) 2018, (IEEE, 2018).

21. T. Komine and M. Nakagawa, "Integrated system of white LED visible-light communication and power-line communication," IEEE Trans. Consum. Electron. 49, 71 (2003).

22. B. S. Ooi, X. Sun, G. Liu, and T. K. Ng, "Ultraviolet FSO to laser-based VLC - the role of group-III-nitride devices," in Asia Communications and Photonics Conference (ACP) 2018, (2018).

23. R. Ji, S. Wang, Q. Liu, and W. Lu, "High-Speed Visible Light Communications: Enabling Technologies and State of the Art," Appl. Sci. 8, 589 (2018).

24. S. Rajbhandari, J. J. McKendry, J. Herrnsdorf, H. Chun, G. Faulkner, H. Haas, I. M. Watson, D. O'Brien, and M. D. Dawson, "A review of gallium nitride LEDs for multigigabit-per-second visible light data communications," Semicond. Sci. and Tech. 32, 023001 (2017).

25. C. V. S. C. Consortium, "Vehicle safety communications project: Task 3 final report: identify intelligent vehicle safety applications enabled by DSRC," National Highway Traffic Safety Administration, US Department of Transportation, Washington DC (2005).

26. X.-W. Ng and W.-Y. Chung, "VLC-based medical healthcare information system," Biomed. Eng. Appl. Basis Commun. 24, 155 (2012)

27. F. Hanson and S. Radic, "High bandwidth underwater optical communication," Appl. Opt. 47, 277 (2008).

28. H. M. Oubei, J. R. Duran, B. Janjua, H.-Y. Wang, C.-T. Tsai, Y.-C. Chi, T. K. Ng, H.-C. Kuo, J.-H. He, and M.-S. Alouini, "4.8 Gbit/s 16-QAM-OFDM transmission based on compact 450-nm laser for underwater wireless optical communication," Opt. Express 23, 23302 (2015).

29 C. Shen, Y. Guo, H. M. Oubei, T. K. Ng, G. Liu, K.-H. Park, K.-T. Ho, M.-S. Alouini, and B. S. Ooi, "20-meter underwater wireless optical communication link with 1.5 Gbps data rate," Opt. Express 24, 25502 (2016).

30. H. M. Oubei, C. Shen, A. Kammoun, E. Zedini, K.-H. Park, X. Sun, G. Liu, C. H. Kang, T. K. Ng, M.-S. Alouini, and B. S. Ooi, "Light based underwater wireless communications," Jpn. J. Appl. Phys. 57(2018).

31. C. Li, H. Lu, W. Tsai, Z. Wang, C. Hung, C. Su, and Y. Lu, "A $5 \mathrm{~m} / 25$ Gbps Underwater Wireless Optical Communication System," IEEE Photonics J. 10, 1 (2018).

32. Y. Chen, M. Kong, T. Ali, J. Wang, R. Sarwar, J. Han, C. Guo, B. Sun, N. Deng, and J. Xu, "26 m/5.5 Gbps air-water optical wireless communication based on an OFDMmodulated 520-nm laser diode," Opt. Express 25, 14760 (2017).

33. M. Kong, W. Lv, T. Ali, R. Sarwar, C. Yu, Y. Qiu, F. Qu, Z. Xu, J. Han, and J. Xu, "10-m 9.51-Gb/s RGB laser diodes-based WDM underwater wireless optical communication," Opt. Express 25, 20829 (2017).

34. C.-Y. Li, H.-H. Lu, W.-S. Tsai, M.-T. Cheng, C.-M. Ho, Y.-C. Wang, Z.-Y. Yang, and D.-Y. Chen, "16 Gb/s PAM4 UWOC system based on 488-nm LD with light injection and optoelectronic feedback techniques," Opt. Express 25, 11598 (2017). 
35. X. Liu, S. Yi, X. Zhou, Z. Fang, Z.-J. Qiu, L. Hu, C. Cong, L. Zheng, R. Liu, and P. Tian, "34.5 m underwater optical wireless communication with $2.70 \mathrm{Gbps}$ data rate based on a green laser diode with NRZ-OOK modulation," Opt. Express 25, 27937 (2017).

36. K. Nakamura, I. Mizukoshi, and M. Hanawa, "Optical wireless transmission of $405 \mathrm{~nm}, 1.45 \mathrm{Gbit} / \mathrm{s}$ optical IM/DD-OFDM signals through a $4.8 \mathrm{~m}$ underwater channel," Opt. Express 23, 1558 (2015).

37. H. M. Oubei, J. R. Durán, B. Janjua, H. Wang, C. Tsai, Y. Chi, T. K. Ng, H. Kuo, H. He, M. Alouini, G. Lin, and B. S. Ooi, "Wireless optical transmission of $450 \mathrm{~nm}, 3.2$ Gbit/s 16-QAM-OFDM signals over $6.6 \mathrm{~m}$ underwater channel," in 2016 Conference on Lasers and ElectroOptics (CLEO), (2016), p. 1.

38. H. M. Oubei, C. Li, K.-H. Park, T. K. Ng, M.-S. Alouini, and B. S. Ooi, "2.3 Gbit/s underwater wireless optical communications using directly modulated $520 \mathrm{~nm}$ laser diode," Opt. Express 23, 20743 (2015).

39. H.-Y. Wang, Y.-F. Huang, W.-C. Wang, C.-T. Tsai, C.-H. Cheng, Y.-C. Chi, and G.-R. Lin, "Seawater Communication with Blue Laser Carried 16-QAM OFDM at 3.7 GBaud," in Optical Fiber Communication Conference, (2018), p. 1.

40. Y. Huang, C. Tsai, Y. Chi, D. Huang, and G. Lin, "Filtered Multicarrier OFDM Encoding on Blue Laser Diode for 14.8-Gbps Seawater Transmission," J. Light. Technol. 36, 1739 (2018).

41. T. H. Runcorn, T. Legg, R. T. Murray, E. J. R. Kelleher, S. V. Popov, and J. R. Taylor, "Fiber-integrated frequencydoubling of a picosecond Raman laser to $560 \mathrm{~nm}$," Opt. Express 23, 15728 (2015).

42. S. Nakamura, S. Pearton, and G. Fasol, The Blue Laser Diode (Springer-Verlag Berlin Heidelberg, 2000).

43. M. C. Schmidt, K. C. Kim, R. M. Farrell, D. F. Feezell, D. A. Cohen, M. Saito, K. Fujito, J. S. Speck, S. P. Denbaars, and S. Nakamura, "Demonstration of nonpolar m-plane InGaN/GaN laser diodes," Jpn. J. Appl. Phys. 2 46, L190 (2007).

44. C. Shen, J. Leonard, A. Pourhashemi, H. Oubei, M. S. Alias, T. K. Ng, S. Nakamura, S. P. DenBaars, J. S. Speck, A. Y. Alyamani, M. M. Eldesouki, and B. S. Ooi, "Low modulation bias InGaN-based integrated EA-modulatorlaser on semipolar GaN substrate," in 2015 IEEE Photonics Conference (IPC), (2015), p. 581.

45. A. Kafar, S. Stanczyk, M. Sarzynski, S. Grzanka, J. Goss, G. Targowski, A. Nowakowska-Siwinska, T. Suski, and P. Perlin, "Nitride superluminescent diodes with broadened emission spectrum fabricated using laterally patterned substrate," Opt. Express 24, 9673 (2016).

46. C. Shen, C. Lee, T. K. Ng, S. Nakamura, J. S. Speck, S. P. DenBaars, A. Y. Alyamani, M. M. El-Desouki, and B. S. Ooi, "High-speed 405-nm superluminescent diode (SLD) with $807-\mathrm{MHz}$ modulation bandwidth," Opt. Express 24, 20281 (2016).

47. C. Shen, T. K. Ng, J. T. Leonard, A. Pourhashemi, S. Nakamura, S. P. DenBaars, J. S. Speck, A. Y. Alyamani, M. M. El-desouki, and B. S. Ooi, "High-brightness semipolar $\left(2021^{-}\right)$blue InGaN/GaN superluminescent diodes for droop-free solid-state lighting and visible-light communications," Opt. Lett. 41, 2608 (2016).

48. C. Shen, T. K. Ng, J. T. Leonard, A. Pourhashemi, H. M. Oubei, M. S. Alias, S. Nakamura, S. P. DenBaars, J. S. Speck, A. Y. Alyamani, M. M. Eldesouki, and B. S. Ooi, "High-modulation-efficiency, integrated waveguide modulator-laser diode at $448 \mathrm{~nm}, "$ ACS Photonics 3, 262 (2016).

49. G. R. Goldberg, A. Boldin, S. M. L. Andersson, P. Ivanov, N. Ozaki, R. J. E. Taylor, D. T. D. Childs, K. M. Groom, K. L. Kennedy, and R. A. Hogg, "Gallium nitride superluminescent light emitting diodes for optical coherence tomography applications," IEEE J. Sel. Topics Quantum Electron, 23, 1 (2017).

$50 . \quad$ C. Shen, T. K. Ng, C. Lee, S. Nakamura, J. S. Speck, S. P. DenBaars, A. Y. Alyamani, M. M. El-Desouki, and B. S. Ooi, "Semipolar InGaN quantum-well laser diode with integrated amplifier for visible light communications," Opt. Express 26, A219 (2018).

51. A. A. Alatawi, J. A. Holguin-Lerma, C. H. Kang, C. Shen, R. C. Subedi, A. M. Albadri, A. Y. Alyamani, T. K. Ng, and B. S. Ooi, "High-power blue superluminescent diode for high CRI lighting and high-speed visible light communication," Opt. Express 26, 26355 (2018).

52. J. Piprek, Nitride semiconductor devices: principles and simulation (Wiley-VCH, 2007).

53. K. M. Kelchner, R. M. Farrell, Y. D. Lin, P. S. Hsu, M. T. Hardy, F. Wu, D. A. Cohen, H. Ohta, J. S. Speck, S. Nakamura, and S. P. DenBaars, "Continuous-Wave Operation of Pure Blue AlGaN-Cladding-Free Nonpolar InGaN/GaN Laser Diodes," Appl. Phys. Express 3(2010).

54. K. M. Kelchner, S. P. DenBaars, and J. S. Speck, "Chapter 4 - GaN Laser Diodes on Nonpolar and Semipolar Planes," in Semiconductors and Semimetals, J. J. Coleman, A. C. Bryce, and C. Jagadish, eds. (Elsevier, 2012), pp. 149.

55. L. Y. Kuritzky and J. S. Speck, "Lighting for the 21 st century with laser diodes based on non-basal plane orientations of GaN," MRS Commun. 5, 463 (2015).

56. C. Shen, Y. Guo, X. Sun, G. Liu, K. T. Ho, T. K. Ng, M. S. Alouini, and B. S. Ooi, "Going beyond 10-meter, Gbit/s underwater optical wireless communication links based on visible lasers," in 2017 Opto-Electronics and Communications Conference (OECC) and Photonics Global Conference (PGC), (2017), p. 1.

57. A. Pourhashemi, R. M. Farrell, M. T. Hardy, P. S. Hsu, K. M. Kelchner, J. S. Speck, S. P. DenBaars, and S. Nakamura, "Pulsed high-power AlGaN-cladding-free blue laser diodes on semipolar (20(2)over-bar(1)over-bar) GaN substrates," Appl. Phys. Lett. 103(2013).

58. J. H. Kang, O. Kruger, U. Spengler, U. Zeimer, S. Einfeldt, and M. Kneissl, "On the formation of cleaved mirror facets of GaN-based laser diodes-A comparative study of diamond-tip edge-scribing and laser scribing," J. Vac. Sci. Technol. B 34(2016).

59. S. P. Najda, P. Perlin, T. Suski, L. Marona, M. Leszczynski, P. Wisniewski, R. Czernecki, R. Kucharski, G. Targowski, M. A. Watson, H. White, S. Watson, and A. E. Kelly, "AlGaInN laser diode technology for $\mathrm{GHz}$ high-speed visible light communication through plastic optical fiber and water," Opt. Eng. 55(2016).

$60 . \quad$ C. Lee, C. Zhang, D. L. Becerra, S. Lee, C. A. Forman, S. H. Oh, R. M. Farrell, J. S. Speck, S. Nakamura, J. E. Bowers, and S. P. DenBaars, "Dynamic characteristics of $410 \mathrm{~nm}$ semipolar (20(2)over-bar(1)over-bar) III-nitride laser diodes with a modulation bandwidth of over $5 \mathrm{GHz}$," Appl. Phys. Lett. 109, 27 (2016).

61. S. Mehari, D. A. Cohen, D. L. Becerra, S. Nakamura, and S. P. Denbaars, "Demonstration of enhanced continuouswave operation of blue laser diodes on a semipolar 20(21)over-bar GaN substrate using indium-tin-oxide/thinp-GaN cladding layers," Opt. Express 26, 1564 (2018). 

"Research on phosphor-conversion laser-based white light used as optical source of VLC and illumination," Opt. Quan. Electron. 49(2017).

63. A. Myzaferi, A. H. Reading, R. M. Farrell, D. A. Cohen, S. Nakamura, and S. P. Denbaars, "Semipolar III-nitride laser diodes with zinc oxide cladding," Opt. Express 25, 16922 (2017).

64. P. S. Hsu, R. M. Farrell, J. J. Weaver, K. Fujito, S. P. DenBaars, J. S. Speck, and S. Nakamura, "Comparison of Polished and Dry Etched Semipolar (11(2)over-bar2) IIINitride Laser Facets," IEEE Photon. Technol. Lett. 25, 2105 (2013).

65. M. T. Hardy, C. O. Holder, D. F. Feezell, S. Nakamura, J. S. Speck, D. A. Cohen, and S. P. DenBaars, "Indium-tinoxide clad blue and true green semipolar InGaN/GaN laser diodes," Appl. Phys. Lett. 103(2013).

$66 . \quad$ B. Xue, Z. Liu, J. Yang, L. S. Feng, N. Zhang, J. X. Wang, and J. M. Li, "Characteristics of III-nitride based laser diode employed for short range underwater wireless optical communications," Opt. Commun. 410, 525 (2018).

67. S. Takagi, Y. Enya, T. Kyono, M. Adachi, Y. Yoshizumi, T. Sumitomo, Y. Yamanaka, T. Kumano, S. Tokuyama, K. Sumiyoshi, N. Saga, M. Ueno, K. Katayama, T. Ikegami, T. Nakamura, K. Yanashima, H. Nakajima, K. Tasai, K. Naganuma, N. Fuutagawa, Y. Takiguchi, T. Hamaguchi, and M. Ikeda, "High-Power (over $100 \mathrm{~mW}$ ) Green Laser Diodes on Semipolar $\{20(2)$ over-bar1 $\}$ GaN Substrates Operating at Wavelengths beyond 530 nm," Appl. Phys. Express 5(2012).

68. J. Yang, D. G. Zhao, D. S. Jiang, X. Li, F. Liang, P. Chen, J. J. Zhu, Z. S. Liu, S. T. Liu, L. Q. Zhang, and M. Li, "Performance of InGaN based green laser diodes improved by using an asymmetric InGaN/InGaN multi-quantum well active region," Opt. Express 25, 9595 (2017).

69. J. Yang, D. Zhao, D. Jiang, P. Chen, J. Zhu, Z. Liu, X. Li, F. Liang, W. Liu, S. Liu, L. Zhang, H. Yang, J. Zhang, and M. Li, "Performance Enhanced by Inserting an InGaN/GaN Shallower-Quantum Well Layer in InGaN Based Green Laser Diodes," IEEE Photonics J. 9, 1 (2017).

70. Y. Xing, D. G. Zhao, D. S. Jiang, X. Li, F. Liang, P. Chen, J. J. Zhu, Z. S. Liu, J. Yang, W. Liu, S. T. Liu, L. Q. Zhang, and M. Li, "Suppression of hole leakage by adding a hole blocking layer prior to the first quantum barrier in $\mathrm{GaN}$ based near-ultraviolet laser diodes," Phys. Status Solidi A 214(2017).

71. A. Q. Tian, J. P. Liu, L. Q. Zhang, Z. C. Li, M. Ikeda, S. M. Zhang, D. Y. Li, P. Y. Wen, F. Zhang, Y. Cheng, X. W. Fan, and H. Yang, "Green laser diodes with low threshold current density via interface engineering of InGaN/GaN quantum well active region," Opt. Express 25, 415 (2017).

72. G. Muziol, H. Turski, M. Siekacz, S. Grzanka, P. Perlin, and C. Skierbiszewski, "Elimination of leakage of optical modes to $\mathrm{GaN}$ substrate in nitride laser diodes using a thick InGaN waveguide," Appl. Phys. Express 9(2016).

73. D. Sizov, R. Bhat, J. Wang, and C. E. Zah, "Reliability and degradation of InAlGaN semipolar (20\$(2)over-bar-\$1) plane green lasers with relaxed InGaN waveguide core," Appl. Phys. Express 7(2014).

74. J. Rass, S. Ploch, T. Wernicke, M. Frentrup, M. Weyers, and M. Kneissl, "Waveguide Optimization for Semipolar (In,Al,Ga)N Lasers," Jpn. J. Appl. Phys. 52(2013).

75. G. Muziol, H. Turski, M. Siekacz, M. Sawicka, P. Wolny, C. Cheze, G. Cywinski, P. Perlin, and C. Skierbiszewski,
"Waveguide Design for Long Wavelength InGaN Based Laser Diodes," Acta Phys. Pol. A 122, 1031 (2012).

76. S. Okawara, Y. Aoki, M. Kuwabara, Y. Takagi, J. Maeda, and H. Yoshida, "Nitride-based stacked laser diodes with a tunnel junction," Appl. Phys. Express 11(2018).

77. B. P. Yonkee, E. C. Young, C. Lee, J. T. Leonard, S. P. DenBaars, J. S. Speck, and S. Nakamura, "Demonstration of a III-nitride edge-emitting laser diode utilizing a GaN tunnel junction contact," Opt. Express 24, 7816 (2016).

78. M. X. Feng, J. P. Liu, S. M. Zhang, D. S. Jiang, Z. C. Li, K. Zhou, D. Y. Li, L. Q. Zhang, F. Wang, H. Wang, P. Chen, Z. S. Liu, D. G. Zhao, Q. Sun, and H. Yang, "High efficient GaN-based laser diodes with tunnel junction," Appl. Phys. Lett. 103(2013).

79. A. Pourhashemi, R. M. Farrell, D. A. Cohen, D. L. Becerra, S. P. DenBaars, and S. Nakamura, "CW operation of highpower blue laser diodes with polished facets on semi-polar (20(2)over-bar(1)over-bar) GaN substrates," Electron. Lett. 52, 2003 (2016).

80. L. Y. Kuritzky, D. L. Becerra, A. S. Abbas, J. Nedy, S. Nakamura, S. P. DenBaars, and D. A. Cohen, "Chemically assisted ion beam etching of laser diode facets on nonpolar and semipolar orientations of GaN," Semicond. Sci. and Tech. 31(2016).

81. H. Le Minh, D. O'Brien, G. Faulkner, L. B. Zeng, K. Lee, D. Jung, Y. Oh, and E. T. Won, "100-Mb/s NRZ Visible Light Communications Using a Postequalized White LED," IEEE Photon. Technol. Lett. 21, 1063 (2009).

82. C. L. Liao, C. L. Ho, Y. F. Chang, C. H. Wu, and M. C. $\mathrm{Wu}$, "High-Speed Light-Emitting Diodes Emitting at 500 nm With 463-MHz Modulation Bandwidth," IEEE Electron Device Lett. 35, 563 (2014).

83. J. J. D. McKendry, R. P. Green, A. E. Kelly, Z. Gong, B. Guilhabert, D. Massoubre, E. D. Gu, and M. D. Dawson, "High-Speed Visible Light Communications Using Individual Pixels in a Micro Light-Emitting Diode Array," IEEE Photon. Technol. Lett. 22, 1346 (2010).

84. L. A. Coldren, S. W. Corzine, and M. L. Mashanovitch, Diode Lasers and Photonic Integrated Circuits (Wiley, 2012).

85. M. N. Ngo, H. T. Nguyen, C. Gosset, D. Erasme, Q. Deniel, N. Genay, R. Guillamet, N. Lagay, J. Decobert, F. Poingt, and R. Brenot, "ElectroAbsorption Modulated Laser Integrated with a Semiconductor Optical Amplifier for 100-km 10.3 Gb/s Dispersion-Penalty-Free Transmission," J. Light. Technol. 31, 232 (2013).

86. C. Shen, C. Lee, T. K. Ng, J. S. Speck, S. Nakamura, S. P. DenBaars, A. Y. Alyamani, M. M. Eldesouki, and B. S. Ooi, "GHz modulation enabled using large extinction ratio waveguide-modulator integrated with $404 \mathrm{~nm}$ GaN laser diode," in 2016 IEEE Photonics Conference (IPC), (2016), p. 813.

87. C. Shen, C. Lee, T. K. Ng, S. Nakamura, J. S. Speck, S. P. DenBaars, A. Y. Alyamani, M. M. El-Desouki, and B. S. Ooi, "High gain semiconductor optical amplifier - Laser diode at visible wavelength," in 2016 IEEE International Electron Devices Meeting (IEDM), (2016), p. 22.4.1.

88. D. F. Feezell, J. S. Speck, S. P. DenBaars, and S. Nakamura, "Semipolar (20-2-1) InGaN/GaN LightEmitting Diodes for High-Efficiency Solid-State Lighting," J. Display. Technol. 9, 190 (2013).

89. F. Kish, R. Nagarajan, D. Welch, P. Evans, J. Rossi, J. Pleumeekers, A. Dentai, M. Kato, S. Corzine, R. Muthiah, M. Ziari, R. Schneider, M. Reffle, T. Butrie, D. Lambert, M. Missey, V. Lal, M. Fisher, S. Murthy, R. Salvatore, S. 
Demars, A. James, and C. Joyner, "From Visible LightEmitting Diodes to Large-Scale III-V Photonic Integrated Circuits," Proc. IEEE 101, 2255 (2013).

90. M. Haurylau, G. Q. Chen, H. Chen, J. D. Zhang, N. A. Nelson, D. H. Albonesi, E. G. Friedman, and P. M. Fauchet, "On-chip optical interconnect roadmap: Challenges and critical directions," IEEE J. Sel. Topics Quantum Electron, 12, 1699 (2006).

91. C. Shen, C. Lee, E. Stegenburgs, J. H. Lerma, T. K. Ng, S. Nakamura, S. P. DenBaars, A. Y. Alyamani, M. M. ElDesouki, and B. S. Ooi, "Semipolar III-nitride quantum well waveguide photodetector integrated with laser diode for on-chip photonic system," Appl. Phys. Express 10, 042201 (2017).

92. C. Shen, C. Lee, T. K. Ng, J. S. Speck, S. Nakamura, S. P. DenBaars, and B. S. Ooi, "Integrated photonic platform based on semipolar InGaN/GaN multiple section laser diodes," in 2017 Conference on Lasers and Electro-Optics Pacific Rim (CLEO-PR), (2017), p. 1.

93. W. Cai, X. M. Gao, W. Yuan, Y. C. Yang, J. L. Yuan, H. B. Zhu, and Y. J. Wang, "Integrated p-n junction InGaN/GaN multiple-quantum-well devices with diverse functionalities," Appl. Phys. Express 9(2016).

94. Z. Y. Jiang, M. R. M. Atalla, G. J. You, L. Wang, X. Y. Li, J. Liu, A. M. Elahi, L. Wei, and J. Xu, "Monolithic integration of nitride light emitting diodes and photodetectors for bi-directional optical communication," Opt. Lett. 39, 5657 (2014).

95. J. Pereiro, C. Rivera, A. Navarro, E. Munoz, R. Czernecki, S. Grzanka, and M. Leszczynski, "Optimization of InGaNGaN MQW Photodetector Structures for HighResponsivity Performance," IEEE J. Quant. Electron. 45, 617 (2009).

96. Y. D. Jhou, C. H. Chen, R. W. Chuang, S. J. Chang, Y. K. Su, P. C. Chang, P. C. Chen, H. Hung, S. M. Wang, and C. L. Yu, "Nitride-based light emitting diode and photodetector dual function devices with InGaN/GaN multiple quantum well structures," Solid-State Electron. 49, 1347 (2005).

97. C. Shen, T. K. Ng, C. Lee, J. T. Leonard, S. Nakamura, J. S. Speck, S. P. Denbaars, A. Y. Alyamani, M. M. ElDesouki, and B. S. Ooi, "Semipolar InGaN-based superluminescent diodes for solid-state lighting and visible light communications," in SPIE OPTO, (2017), p. 10.

98. E. Feltin, A. Castiglia, G. Cosendey, L. Sulmoni, J.-F. Carlin, N. Grandjean, M. Rossetti, J. Dorsaz, V. Laino, M. Duelk, and C. Velez, "Broadband blue superluminescent light-emitting diodes based on GaN," Appl. Phys. Lett. 95, 081107 (2009).

99. T. H. Matthew, M. K. Kathryn, L. You-Da, H. Po Shan, F. Kenji, O. Hiroaki, S. S. James, N. Shuji, and P. D. Steven, "m -Plane GaN-Based Blue Superluminescent Diodes Fabricated Using Selective Chemical Wet Etching," Appl. Phys. Express 2, 121004 (2009).

100. R. Marco, D. Julien, R. Raffaele, D. Marcus, V. Christian, F. Eric, C. Antonino, C. Gatien, C. Jean-François, and G. Nicolas, "High Power Blue-Violet Superluminescent Light Emitting Diodes with InGaN Quantum Wells," Appl. Phys. Express 3, 061002 (2010).

101. K. Anna, S. Szymon, T. Grzegorz, O. Takao, M. Irina, W. Przemek, S. Tadek, and P. Piotr, "High-optical-power InGaN superluminescent diodes with "j-shape" waveguide," Appl. Phys. Express 6, 092102 (2013).

102. A. Kafar, S. Stańczyk, P. Wiśniewski, T. Oto, I. Makarowa, G. Targowski, T. Suski, and P. Perlin, "Design and optimization of InGaN superluminescent diodes," Phys. Status Solidi 212, 997 (2015).

103. G. R. Goldberg, P. Ivanov, N. Ozaki, D. T. D. Childs, K. M. Groom, K. L. Kennedy, and R. A. Hogg, "Gallium nitride light sources for optical coherence tomography," in SPIE OPTO, (2017), p. 7.

104. D. C. O'Brien, L. Zeng, H. Le-Minh, G. Faulkner, J. W. Walewski, and S. Randel, "Visible light communications: Challenges and possibilities," in Personal, Indoor and Mobile Radio Communications, 2008. PIMRC 2008. IEEE 19th International Symposium on, (2008), p. 1.

105. H. Chun, P. Manousiadis, S. Rajbhandari, D. A. Vithanage, G. Faulkner, D. Tsonev, J. J. McKendry, S. Videv, X. Enyuan, and G. Erdan, "Visible light communication using a blue $\mathrm{GaN} \mu \mathrm{LED}$ and fluorescent polymer color converter," IEEE Photon. Technol. Lett. 26, 2035 (2014).

106. M. T. Sajjad, P. P. Manousiadis, H. Chun, D. A. Vithanage, S. Rajbhandari, A. L. Kanibolotsky, G. Faulkner, D. O'Brien, P. J. Skabara, and I. D. Samuel, "Novel fast colorconverter for visible light communication using a blend of conjugated polymers," ACS Photonics 2, 194 (2015).

107. G. M. Farinola and R. Ragni, "Electroluminescent materials for white organic light emitting diodes," Chem. Soc. Rev. 40, 3467 (2011).

108. D. Shi, V. Adinolfi, R. Comin, M. Yuan, E. Alarousu, A. Buin, Y. Chen, S. Hoogland, A. Rothenberger, and K. Katsiev, "Low trap-state density and long carrier diffusion in organolead trihalide perovskite single crystals," Science 347, 519 (2015).

109. E. R. Dohner, E. T. Hoke, and H. I. Karunadasa, "Selfassembly of broadband white-light emitters," J. Am. Chem. Soc. 136, 1718 (2014).

110. S. Pathak, N. Sakai, F. Wisnivesky Rocca Rivarola, S. D. Stranks, J. Liu, G. E. Eperon, C. Ducati, K. Wojciechowski, J. T. Griffiths, and A. A. Haghighirad, "Perovskite crystals for tunable white light emission," Chem. Mater. 27, 8066 (2015).

111. P. F. Smet, A. B. Parmentier, and D. Poelman, "Selecting conversion phosphors for white light-emitting diodes," J. Electrochem. Soc. 158, R37 (2011).

112. F. Zhang, H. Zhong, C. Chen, X.-g. Wu, X. Hu, H. Huang, J. Han, B. Zou, and Y. Dong, "Brightly luminescent and color-tunable colloidal $\mathrm{CH} 3 \mathrm{NH} 3 \mathrm{PbX} 3(\mathrm{X}=\mathrm{Br}, \mathrm{I}, \mathrm{Cl})$ quantum dots: potential alternatives for display technology," ACS Nano 9, 4533 (2015).

113. G. Nedelcu, L. Protesescu, S. Yakunin, M. I. Bodnarchuk, M. J. Grotevent, and M. V. Kovalenko, "Fast anionexchange in highly luminescent nanocrystals of cesium lead halide perovskites $(\mathrm{CsPbX} 3, \mathrm{X}=\mathrm{Cl}, \mathrm{Br}, \mathrm{I})$," Nano Lett. 15, 5635 (2015).

114. J. Pan, S. P. Sarmah, B. Murali, I. Dursun, W. Peng, M. R. Parida, J. Liu, L. Sinatra, N. Alyami, and C. Zhao, "Airstable surface-passivated perovskite quantum dots for ultra-robust, single-and two-photon-induced amplified spontaneous emission," J. Phys. Chem. Lett. 6, 5027 (2015).

115. C. Cozzan, G. Lheureux, N. O’Dea, E. E. Levin, J. Graser, T. D. Sparks, S. Nakamura, S. P. DenBaars, C. Weisbuch, and R. Seshadri, "Stable, Heat-Conducting Phosphor Composites for High-Power Laser Lighting," ACS Appl. Mater. Interfaces 10, 5673 (2018).

116. J. Proakis, Digital Communications, 5th ed. (McGraw-Hill Education, 2007).

117. B. P. Lathi, Modern Digital and Analog Communication Systems, 2nd ed. (Oxford University Press, Inc., 1995). 
118. L. N. Binh, Advanced Digital Optical Communications, 2nd ed. (CRC Press, 2015).

119. A. Al-halafi, H. M. Oubei, B. S. Ooi, and B. Shihada, "Real-Time Video Transmission Over Different Underwater Wireless Optical Channels Using a Directly Modulated $520 \mathrm{~nm}$ Laser Diode," IEEE/OSA J. Opt. Commun. Netw. 9, 826 (2017).

120. H. S. Kim, D. R. Kim, S. H. Yang, Y. H. Son, and S. K. Han, "Mitigation of inter-cell interference utilizing carrier allocation in visible light communication system," IEEE Commun. Lett. 16, 526 (2012).

121. Y. C. Chi, D. H. Hsieh, C. Y. Lin, H. Y. Chen, C. Y. Huang, J. H. He, B. Ooi, S. P. DenBaars, S. Nakamura, H. C. Kuo, and G. R. Lin, "Phosphorous Diffuser Diverged Blue Laser Diode for Indoor Lighting and Communication," Sci. Rep. 5, 1 (2015).

122. H. Chun, S. Rajbhandari, D. Tsonev, G. Faulkner, H. Haas, and D. O. Brien, "Visible light communication using laser diode based remote phosphor technique," in 2015 IEEE International Conference on Communication Workshop (ICCW), (2015), p. 1392.

123. N. Chi, LED-Based Visible Light Communications (Springer, 2018).

124. A. Shlomi, J. Barry, G. Karagiannidis, R. Schober, and M. Uysal, Advanced Optical Wireless Communication Systems, 1st ed. (Cambridge University Press, 2012).

125. A. Jovicic, J. Li, and T. Richardson, "Visible light communication: Opportunities, challenges and the path to market," IEEE. Commun. Mag. 51, 26 (2013).

126. H. Burchardt, N. Serafimovski, D. Tsonev, S. Videv, and H. Haas, "VLC: Beyond point-to-point communication," IEEE. Commun. Mag. 52, 98 (2014).

127. C. W. Chow, C. H. Yeh, Y. F. Liu, and P. Y. Huang, "Mitigation of optical background noise in light-emitting diode (LED) optical wireless communication systems," IEEE Photonics J. 5, 0 (2013). 